\title{
Edificios en clima cálido húmedo. Caso de Tampico, Tamaulipas. Tamaulipas. México
}

Mireya Rosas Lusett ${ }^{1}$ | Jaume Roset Calzada ${ }^{2}$ Helena Coch Roura ${ }^{3}$

Recibido: 03-07-2018 | en su versión final: 18-05-2020

Resumen

El objetivo de este trabajo es analizar en corto tiempo y recursos propios, el comportamiento ambiental de los edificios del Multifamiliar, para extraer recomendaciones aplicables a las nuevas edificaciones de interés social que carecen de diseño bioclimático en clima cálido húmedo. La metodología se divide en cuatro etapas: 1 Realizar estudio del clima de Tampico de los años 1991 a 2010 del Sistema Meteorológico Nacional y del 2012 al 2013 de la estación meteorológica de la FADU-UAT. 2. Determinar las zonas de confort permisible, ventilación natural y necesidades de enfriamiento con aire acondicionado, con dos softwares Comfort Ex y Heliodon, y analizar con diagrama psicrométrico. 3. Evaluar los edificios, con estudio básico de sombras y ángulos solares en Heliodon. 4. Analizar las fachadas y vegetación de los edificios, con temperatura de superficie, arborización existente, velocidad y dirección del flujo de viento. Como conclusiones, el estudio evidencia los meses críticos de abril a octubre, la necesidad de protección solar en verano en todas las fachadas durante todo el día. La mejor orientación para un edificio es la Norte-Sur. Las fachadas más críticas son la Oeste, Noroeste y Suroeste. La separación entre los edificios permitió que el viento fluyera sin obstrucciones y se mantuvo con dirección Sureste durante todo el día a una velocidad de aire ligero por la mañana y durante la tarde aumentó su velocidad a brisa suave. Se recomienda utilizar vegetación en todas las fachadas para su protección solar, con copas amplias de más de $10 \mathrm{~m}$ de diámetro y mayores de $12 \mathrm{~m}$ de altura.

Palabras clave: Confort térmico; vegetación; radiación solar; viento

Citación

Rosas Lusett, M. et al. (2020). Edificios en clima cálido húmedo. Caso de Tampico, Tamaulipas. México. ACE: Architecture, City and Environment, 15(44), 5667. DOl http://dx.doi.org/10.5821/ace.15.44.5667

\footnotetext{
${ }^{1}$ Dra. Arquitecta, Facultad de Diseño, Arquitectura y Urbanismo, UAT (ORCID ID: 0000-0002-6050-4740; WoS Researcher ID: ANN-7589-2020; Scopus Author ID: 57208237727), ${ }^{2}$ Dr. en Física, profesor del Departamento de Física, ETSAB, UPC (ORCID ID: 0000-0002-0548-5524; WoS Researcher ID: Q-3224-2017; Scopus Author ID: 55196107300$),{ }^{3}$ Dra. Arquitecta, Catedrática del Departamento de Tecnología de la Arquitectura, ETSAB, UPC (ORCID ID: 0000-0001-9524-8057; WoS Researcher ID: 1-2153-2017; Scopus Author ID: 6603101372). Correo de contacto: mrosas@docentes.uat.edu.mx
} 


\section{Buildings in warm humid weather. Tampico, Tamaulipas case. Mexico}

Abstract The objective of this work is the analysis in short time and with internal resources, of the environmental behavior of Multifamily buildings, to produce applicable recommendations for new social interest constructions lacking a bioclimatic design a warm humid weather. The methodology is divided into four: 1 . The study of Tampico's weather from 1991 to 2010 by the National Meteorological System and from 2012 to 2013 by the weather station at FADU-UAT. 2. The determination of areas of permissible comfort, natural ventilation and cooling AC needs, with software Comfort Ex and Heliodon and the examination with psychometric diagram. 3. The evaluation of the buildings, with basic shade and solar angle study in Heliodon. 4. The analysis of facades and vegetation of the buildings, with surface temperature, existing vegetation, wind speeds and the flow direction. Conclusions: The study demonstrates the critical months from April to October, the need of solar protection in summertime on all the facades through the entire day. The best orientation for a building is North-South. The most critical facades are West, Northwest and Southwest. Separation between buildings allowed the wind to flow without obstructions and remained directed to the Southeast the whole day at a light air speed during the morning, and during the afternoon, its speed increased to a soft breeze. It is recommended to use vegetation on all facades for their solar protection, with broad tree crowns with more than $10 \mathrm{~m}$ in diameter and higher than $12 \mathrm{~m}$.

Keywords: Thermal comfort; vegetation; solar radiation; wind

\section{Introducción}

El acelerado proceso de urbanización de las últimas décadas se traduce en importantes alteraciones de origen antrópico asociadas al funcionamiento de la ciudad (Terradas et al., 2001). La modificación del ciclo hidrológico, la fragmentación de hábitats, la contaminación y la formación de un clima local específico, son algunos de los mayores impactos ambientales debido a la transformación del medio natural producido por la urbanización.

Las principales modificaciones climáticas que suceden en las áreas urbanas donde la superficie natural ha sido sustituida o cubierta por edificaciones, trae como consecuencia la modificación del movimiento del aire en la superficie; se reduce la velocidad del viento y por otro lado se incrementa la turbulencia. La sustitución del suelo natural por diversos tipos de pavimentos, que permiten una escorrentía rápida, provocan una reducción de la evaporación y de la humedad de la superficie y del aire. Los materiales de construcción urbanos poseen unas propiedades físicas distintas a las del suelo natural. Básicamente, presentan albedos menores y una mayor capacidad calorífica, así como, una buena conductividad térmica. Todo esto modifica el balance de radiación urbano, influyendo sobre la temperatura del aire. Moreno (1993).

Serra y Coch (2001), explican que los espacios exteriores de cada lugar tienen diferentes intercambios energéticos, que se resumen como las preexistencias ambientales; para analizar un 
espacio es necesario conocer la radiación solar, temperatura del aire, humedad relativa, movimiento del aire, viento, entre otros.

La radiación solar es el parámetro que tiene mayor impacto en los espacios abiertos, se debe considerar altura y distancia de los edificios colindantes, y los de enfrente, pues las características de éstos pueden provocar que aumente considerablemente el aporte energético. Se destaca el estudio de López-Ordoñez et al (2017), de la relación de la morfología de las calles y su vegetación. La orientación de las calles y el Factor de Vista de Cielo (FVC), son los factores que determinan los esquemas de radiación solar de los edificios durante el año, a lo largo de sus fachadas y en los espacios entre los edificios, modificando el confort en los espacios interiores.

La vegetación es una herramienta valiosa para el control de la temperatura del aire y superficial a escala microclimática, Ochoa (2009) describe que se pueden implementar cuatro acciones: (1) pantallas sombreadoras, para evitar que las demás superficies se calienten y transfieran su calor por convección al aire; (2) cielo raso frío; al utilizar la vegetación que tiene una menor capacidad calorífica, y pasar por el proceso de evapotranspiración y tener una menor densidad, que los materiales constructivos, no emite tanta radiación de onda larga hacia los usuarios, cuando se usa como parte de la techumbre o en una pérgola; (3) protección contra el viento, la vegetación se puede usar como barrera para proteger de la acción del viento en espacios que están siendo acondicionados por otros medios; (4) superficies frescas, las coberturas superficiales, se mantienen más frías que los pavimentos hechos de materiales pétreos, además retienen el agua de la irrigación.

El movimiento del aire en la ciudad está condicionado por los edificios, las calles, las plazas, los espacios abiertos y la vegetación existente. El régimen general de vientos es modificado por el tejido urbano, donde varía la densidad urbana y las posibles canalizaciones de vientos a lo largo de las zonas libres y áreas verdes, así como la edificación en altura pueden variar la dirección y la velocidad (Higueras, 2006). El flujo del viento debe utilizarse para refrescar durante la época de calor y en los periodos donde los valores de humedad relativa son muy altos. Por el contrario, deberá bloquearse el movimiento del aire o evitarse durante tiempo de frío.

Olgyay (2006), manifiesta que la adaptación a la orientación de los vientos en los edificios de poca altura, no constituye un aspecto relevante, en los cuales el empleo de barreras contra el viento, la disposición de las aberturas en las zonas de alta o baja presión y el efecto direccional de elementos de control en las ventanas, puede mejorar la situación del flujo de viento. Sin embargo, para las construcciones altas, como edificaciones de viviendas, oficinas y hospitales que no tienen aire acondicionado, y el terreno circundante tiene poco efecto en las plantas superiores, se deberá tener en cuenta la orientación en relación al viento. Tomando en cuenta, las condiciones anualesmensuales predominantes de la velocidad, y temperatura del viento según su dirección.

\subsection{El confort en espacios exteriores}

La utilización de los espacios abiertos está unida a la obtención de ciertos niveles de confort aceptables en dichos espacios. En los espacios abiertos, no se pretende alcanzar una sensación de bienestar como la que se da en espacios interiores climatizados. Ochoa (2009).

El uso de los espacios exteriores está relacionado con el confort urbano, resultado de la percepción de las personas cuando usan y disfrutan el espacio. El grado de bienestar que el entorno es capaz de proporcionar, debe satisfacer las necesidades básicas, sin tener que agotar los recursos naturales. El estado de bienestar óptimo es consecuencia de alcanzar un equilibrio entre el hombre y su medio ambiente (Rein, 2013). 
El diagrama bioclimático del Olygay es el que se utiliza para analizar los espacios exteriores, incluso es la base del Comfort Ex. Para el estudio de confort en los espacios interiores, el diagrama psicrométrico es un método bioclimático propuesto por Givoni (1976) basado en el de Olygay. Está formado por un sistema de coordenadas que representan las propiedades termodinámicas del aire húmedo. En él se sitúa la zona de confort, que se extiende, con determinadas estrategias. Para las zonas húmedas y tropicales, la ventilación natural es el sistema de refrigeración más adecuado, aprovechando los vientos y las brisas, facilitando las pérdidas de calor por el cuerpo por convección, evaporación, reduciendo el malestar térmico debido al alto grado de humedad relativa.

\subsection{Los conjuntos habitacionales de interés social en Tampico, Tamaulipas. México}

En los últimos años se han edificado con diversas tipologías en los bloques de manzana, viviendas de uno o dos niveles generalmente adosadas. De acuerdo al Instituto Nacional de Estadística y Geografía (INEGI) 2010, en 1995 había 68,354 viviendas y en el 2010 se alcanzó la cifra de 86,307 viviendas, lo que se traduce en un aumento del 26\% en cinco años; considerando que la población pasó de 278,933 a 297,554 habitantes, se prevé que para el 2030 existan 363,089 habitantes. Es conveniente que las nuevas edificaciones reúnan las condiciones adecuadas de confort térmico, acústico, ambiental con espacios microclimáticamente adecuados a los usos de la localidad y de su clima para reducir el consumo de energías convencionales contaminantes.

Los nuevos desarrollos habitacionales en Tampico, Tamaulipas (Figura 1), se han proyectado con más vialidades, escasas áreas verdes y reducida densidad de población, comparados con los construidos en la ciudad de México por Mario Pani (1947-1949 y 1950-1953) de alta densidad, y el único de su tipo, construido en Tampico Tamaulipas, México por el Ing. Alejandro Prieto en la colonia Otomí. La redensificación con diseño bioclimático es una alternativa para climas cálidos húmedos, ya que al disminuir el impacto de la radiación solar se verá reflejado en la reducción en el consumo de refrigeración y más horas de confort en las áreas de recreación y espacios de encuentro.

Figura 1. Fraccionamientos habitacionales ubicados en colonia Jardines de Arboledas. Tampico, Tamaulipas, México
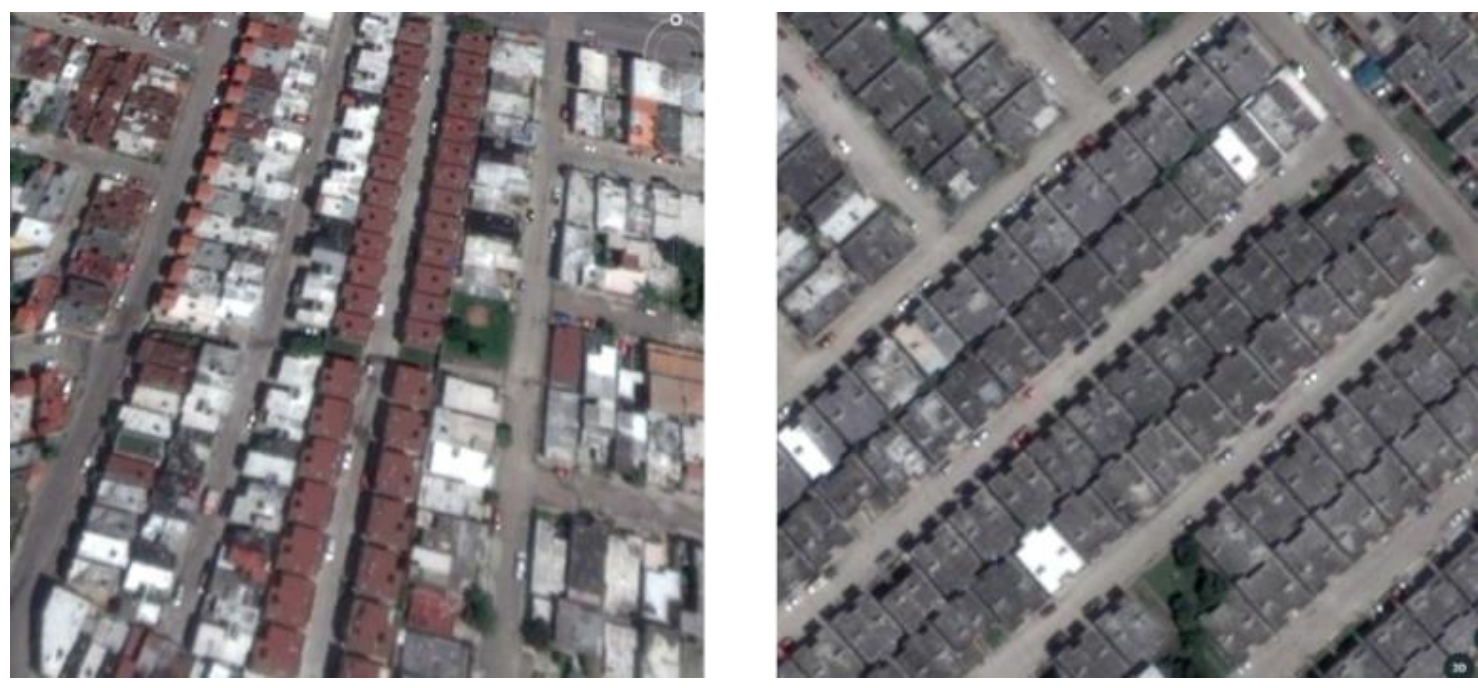

Fuente: Google Earth (2018). 
Higueras (2012) menciona que la oportunidad de aumentar la vivienda en sentido vertical en los desarrollos residenciales es procedente, desde un punto de vista de la sostenibilidad. A mayor densidad, más masa crítica de ciudadanos para mejorar los ejes de actividad, las zonas comerciales, el espacio público e incrementar la seguridad en las calles.

\section{Estudio del clima de Tampico de los años 1981 a 2010 del SMN y del 2012 al 2013 de la estación meteorológica de FADU UAT}

\subsection{Clima de Tampico}

Los datos de temperatura y precipitación provienen de la base de datos del Sistema Meteorológico Nacional, estando la estación climática Tampico, más cercana al área de estudio, localizada en latitud 22 $14^{\prime} 19^{\prime \prime} \mathrm{N}$, longitud 97052'44" W a una altura de 3 MSN; los registros de la estación presentados a continuación comprenden el periodo de 1981-2010.

De acuerdo con el INEGI 2010, el tipo de clima dominante en el área de estudio es representado por Aw1, cálido subhúmedo con lluvias en verano; García (1990) describe el clima de la zona como cálido todo el año. En el periodo 1981- 2010, la temperatura media anual es de $25.1^{\circ} \mathrm{C}$, con temperaturas medias mensuales entre $19.1^{\circ} \mathrm{C}$ y $29.2^{\circ} \mathrm{C}$, con período de canícula, como se muestra en la Tabla 1.

Tabla 1. Temperaturas máximas, medias y mínimas promedio mensuales en ${ }^{\circ} \mathrm{C}$. Periodo $1981-2010$

\begin{tabular}{|c|c|c|c|c|c|c|c|c|c|c|c|c|}
\hline Ta & E & F & M & A & M & J & J & A & S & O & N & D \\
\hline Máx & 23.3 & 24.8 & 27.1 & 29.4 & 31.5 & 32.5 & 32.3 & 32.8 & 31.9 & 30.3 & 27.5 & 24.2 \\
\hline Med & 19.2 & 20.7 & 32.1 & 25.6 & 28.0 & 29.0 & 28.7 & 29.1 & 28.2 & 26.3 & 23.3 & 20.1 \\
\hline Mín & 15.1 & 16.5 & 19.1 & 21.8 & 24.5 & 25.6 & 25.1 & 25.3 & 24.4 & 22.3 & 19.2 & 15.9 \\
\hline
\end{tabular}

Fuente: elaboración propia con datos del Sistema Meteorológico Nacional para Tampico, Tamaulipas.

La oscilación térmica fue mayor en el periodo de febrero del 2012 a enero del 2013 en invierno y otoño de $14^{\circ} \mathrm{C}$, en primavera de $17^{\circ} \mathrm{C}$ y verano de $19^{\circ} \mathrm{C}$. La temperatura media que presenta la zona en la temporada más calurosa, durante el semestre de junio a septiembre, supera los $28^{\circ} \mathrm{C}$; agosto es el mes más caluroso con un registro de $32.8{ }^{\circ} \mathrm{C}$ promedio de las máximas; las mínimas son de diciembre a febrero, siendo el mes de enero el más frío con temperatura promedio de $15.1^{\circ} \mathrm{C}$.

En lo que respecta a los vientos, durante los meses de marzo a octubre se presentan con velocidad promedio de $4.3 \mathrm{~m} / \mathrm{s}$ del Este y de $3.7 \mathrm{~m} / \mathrm{s}$ del Este-Sureste, estos vientos son los que predominan la mayor parte del año. De octubre a febrero son más frecuentes los vientos del Norte con una velocidad entre 3.1 y $6.1 \mathrm{~m} / \mathrm{s}$, y algunas direcciones del Norte-Noroeste-Sureste.

La frecuencia de vientos conocidos como "Nortes", registrados en la zona, establecen un promedio superior a los 30 sucesos, que comprende a los vientos provenientes del Norte por año, iniciando regularmente entre septiembre y octubre, continuando hasta los meses de marzo y abril. Los vientos del Norte llegan a presentar velocidades superiores a los $13.9 \mathrm{~m} / \mathrm{s}$, con velocidades que superan los $25 \mathrm{~m} / \mathrm{s}$; no son frecuentes y duran poco tiempo en la región. Estos vientos del Norte influyen rápidamente en la temperatura, provocando descensos bruscos. García (1990).

De la estación meteorológica de la FADU, se trazaron las rosas de viento, como se observan en la Figura 2. El viento dominante se presenta en los meses de marzo a octubre con dirección Este y Este Sureste, velocidad promedio de $2.5 \mathrm{~m} / \mathrm{s}$. 
Figura 2. Frecuencia y velocidad del viento de marzo a octubre 2012

MARZO
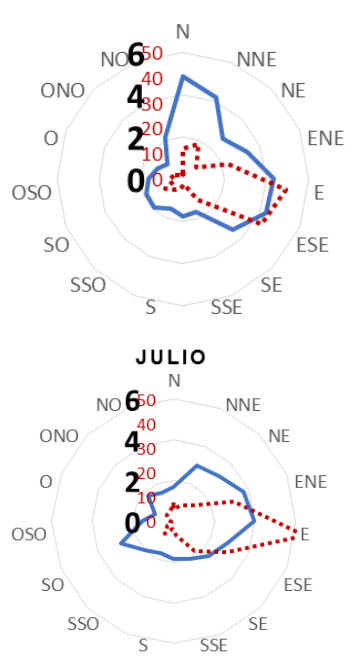

ABRIL
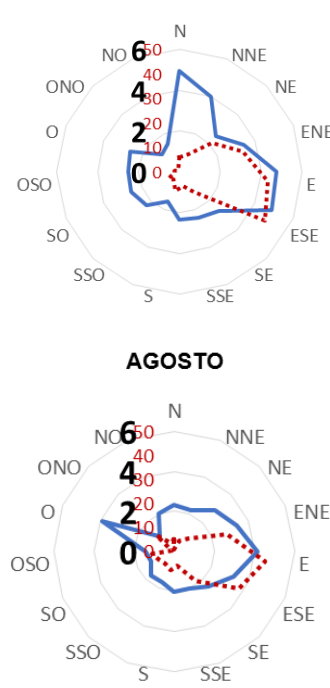

MAYO
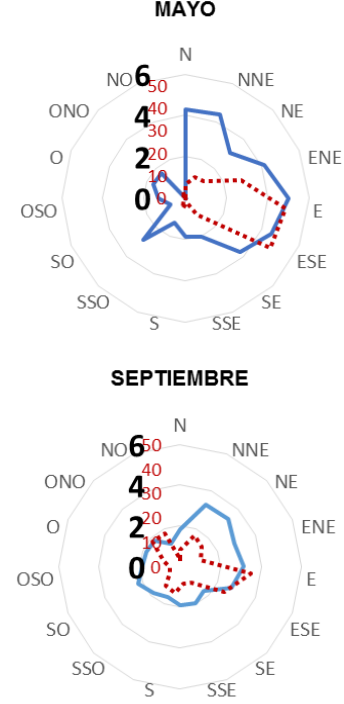

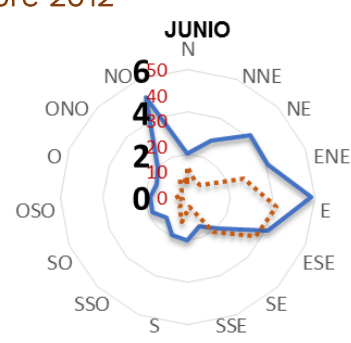

OCTUBRE

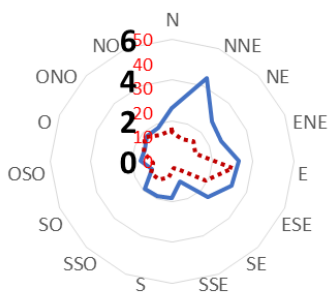

- - - - frecuencia velocidad

Fuente: elaboración propia con datos de estación meteorológica, FADU UAT (2012).

En el SMN CONAGUA, el promedio anual de humedad registrada en Tampico Tamaulipas es de 78\%, siendo por lo general el mes más húmedo septiembre, que coincide con el de más alta precipitación como se observa en la Tabla 2. La humedad relativa más baja registrada es de $50 \%$ en los meses de enero y febrero después del paso de vientos fríos y secos del invierno los antes mencionados "Nortes".

Tabla 2. Precipitación normal 1981-2010

\begin{tabular}{|c|c|c|c|c|c|c|c|c|c|c|c|}
\hline E & F & M & A & M & J & J & A & S & O & N & D \\
\hline 30.5 & 24.7 & 19.4 & 27.1 & 56.8 & 156.8 & 159.8 & 166.8 & 286.2 & 159.2 & 42.0 & 34.2 \\
\hline
\end{tabular}

Fuente: elaboración propia con datos del Sistema Meteorológico Nacional para Tampico, Tamaulipas.

Figura 3. Ubicación de Tampico y los cuerpos de agua que lo rodean

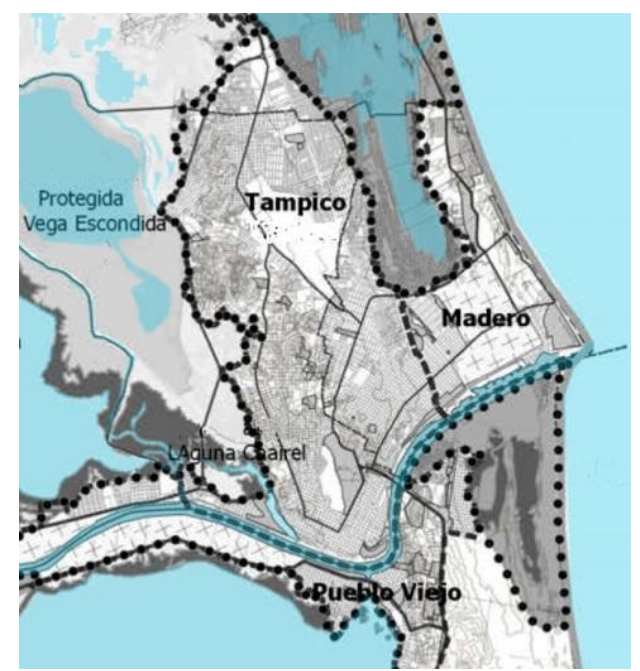

Fuente: Proyecto Integración (2018). 
La zona se encuentra rodeada de agua casi en su totalidad (Figura 3), al Oeste el Sistema Lagunario del Río Tamesí, al Sur el río Pánuco y al Este el Golfo de México. La humedad registrada en la estación meteorología de la FADU UAT de febrero 2012 a enero 2013 presentó un valor promedio de $85 \%$.

En la Figura 4, se observan los valores más altos de humedad superiores al 85\% en marzo, abril, julio, agosto, septiembre, octubre noviembre y enero. Los meses con valores menores al $80 \%$ de humedad son mayo y diciembre. El $81 \%$ de los días del año se encontraron nublados; parcialmente nublados un 40\% y nublado cerrado el 41\%, sólo el 19\% se encontraron despejados.

Figura 4. Gráfica de humedad relativa, febrero 2012 a enero 2013

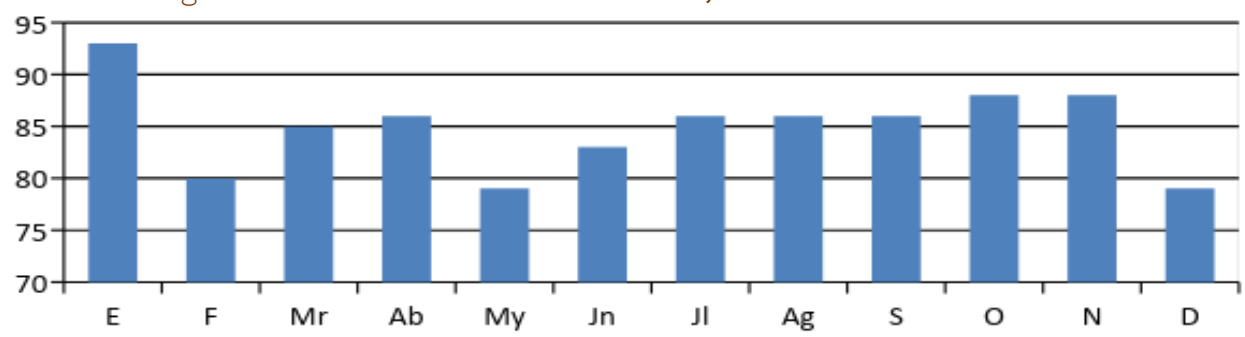

Fuente: elaboración propia basada en la estación meteorológica FADU UAT 2012-2013 de Tampico, Tamaulipas.

Para el alto porcentaje de humedad permanente en Tampico y con temperaturas promedio superiores a los 25o en los meses de abril a octubre, la ventilación es una herramienta a considerar como sistema pasivo. En el espacio urbano la trama debe ser dispersa y los edificios altos y separados con formas porosas y alargadas para que fluya el viento. La ubicación de las viviendas se recomienda en partes altas para aprovechar el viento del Este y Este-Sureste.

En las superficies con topografía plana, deberán tener las pendientes necesarias para la escorrentía del agua para los días de lluvias fuertes. Los pavimentos deben ser permeables o semipermeables en un 40\% de las áreas, para la absorción rápida del agua de lluvia.

La radiación solar, es una forma de energía que se transforma en energía térmica la cual al ser absorbida por las superficies trasmite calor al interior de las edificaciones. Yáñez (2008), en otros, mencionan que, al atravesar la atmosfera, la radiación solar es parcialmente sometida a fenómenos de absorción, refracción, reflexión y difusión, alcanzando la superficie terrestre con una intensidad menor y descompuesta en dos tipos de radiación: radiación directa $G_{D}$, y radiación difusa $G_{d}$

La radiación directa $G_{D}$ es aquella que se recibe del Sol sin haber sufrido ningún cambio de dirección al atravesar la atmosfera. La radiación difusa $G_{d}$ es aquella que se recibe después de haber sufrido cambios de dirección principalmente por reflexión y difusión. La radiación total o global, $G$, es la suma de ambas es decir $G=G_{D}+G_{d}$

En la Tabla 3, se observan los valores de radiación solar medidos con la estación meteorológica FADU UAT, sobre el plano horizontal; se presentan superiores a $600 \mathrm{Wh} / \mathrm{m}^{2}$, en los meses de febrero, marzo, abril, mayo, junio, julio agosto septiembre, y octubre; se destacan los meses de abril, mayo, junio, julio, de 11 a 14 horas que superan los $800 \mathrm{Wh} / \mathrm{m}^{2}$.

El recorrido solar en la localidad de Tampico, Tamaulipas, $22^{\circ} \mathrm{LN}$, se aprecia en las figuras 5 y 6 . En verano el día más largo tiene 15 horas de luz, sale por el Noreste a los 116o desde el Sur, a las doce horas alcanza una altura solar de 89 y se oculta por el Noroeste a los 116o; en invierno el día más corto tiene 11 horas de luz y alcanza una altura solar de 44ํa las doce horas; sale por el Sureste a los 66ㅇy y se oculta por el Suroeste a los 66ㅇ․ 
Tabla 3. Radiación solar global horizontal Wh/m2. Estación meteorológica FADU UAT 2012-2013

\begin{tabular}{|c|c|c|c|c|c|c|c|c|c|c|c|c|}
\hline & $E$ & $\mathrm{~F}$ & M & A & M & J & $J$ & A & $S$ & 0 & $\mathrm{~N}$ & D \\
\hline $0: 01-1: 00$ & 1 & 1 & 1 & 1 & 1 & 1 & 1 & 1 & 1 & 1 & 1 & 1 \\
\hline 1:01- 2:00 & 1 & 1 & 1 & 1 & 1 & 1 & 1 & 1 & 1 & 1 & 1 & 1 \\
\hline $2: 01-3: 00$ & 1 & 1 & 1 & 1 & 1 & 1 & 1 & 1 & 1 & 1 & 1 & 1 \\
\hline $3: 01-4: 00$ & 1 & 1 & 1 & 1 & 1 & 1 & 1 & 1 & 1 & 1 & 1 & 1 \\
\hline $4: 01-5: 00$ & 1 & 1 & 1 & 1 & 1 & 1 & 1 & 1 & 1 & 1 & 1 & 1 \\
\hline $5: 01-6: 00$ & 1 & 1 & 1 & 1 & 2 & 1 & 1 & 1 & 1 & 2 & 2 & 1 \\
\hline $6: 01-7: 00$ & 1 & 1 & 1 & 47 & 58 & 70 & 43 & 39 & 24 & 24 & 9 & 2 \\
\hline 7:01- 8:00 & 16 & 1 & 1 & 151 & 186 & 216 & 167 & 124 & 104 & 136 & 73 & 43 \\
\hline 8:01- 9:00 & 54 & 2 & 5 & 409 & 305 & 400 & 309 & 267 & 176 & 308 & 190 & 157 \\
\hline 9:01-10:00 & 111 & 48 & 58 & 463 & 540 & 552 & 515 & 410 & 303 & 462 & 326 & 321 \\
\hline 10:01-11:00 & 182 & 105 & 195 & 541 & 703 & 630 & 492 & 531 & 512 & 561 & 392 & 448 \\
\hline $11: 01-12: 00$ & 166 & 228 & 320 & 697 & 859 & 766 & 608 & 598 & 660 & 622 & 446 & 517 \\
\hline $12: 01-13: 00$ & 146 & 361 & 442 & 829 & 873 & 891 & 609 & 645 & 703 & 702 & 451 & 546 \\
\hline $13: 01-14: 00$ & 144 & 519 & 530 & 779 & 788 & 837 & 639 & 698 & 690 & 689 & 439 & 500 \\
\hline $14: 01-15: 00$ & 155 & 600 & 676 & 712 & 615 & 754 & 706 & 581 & 596 & 595 & 373 & 456 \\
\hline $15: 01-16: 00$ & 119 & 643 & 659 & 554 & 223 & 580 & 538 & 465 & 468 & 494 & 289 & 313 \\
\hline $16: 01-17: 00$ & 61 & 614 & 570 & 355 & 66 & 424 & 396 & 348 & 316 & 300 & 154 & 155 \\
\hline 17:01-18:00 & 16 & 413 & 485 & 184 & 3 & 248 & 250 & 192 & 131 & 100 & 41 & 36 \\
\hline 18:01-19:00 & 1 & 269 & 334 & 36 & 1 & 81 & 85 & 61 & 19 & 7 & 1 & 1 \\
\hline 19:01-20:00 & 1 & 140 & 160 & 1 & 1 & 8 & 12 & 1 & 1 & 1 & 1 & 1 \\
\hline 20:01-21:00 & 1 & 26 & 34 & 1 & 1 & 1 & 1 & 1 & 1 & 1 & 1 & 1 \\
\hline 21:01-22:00 & 1 & 1 & 1 & 1 & 1 & 1 & 1 & 1 & 1 & 1 & 1 & 1 \\
\hline 22:01-23:00 & 1 & 1 & 1 & 1 & 1 & 1 & 1 & 1 & 1 & 1 & 1 & 1 \\
\hline 23:01-24:00 & 1 & 1 & 1 & 1 & 1 & 1 & 1 & 1 & 1 & 1 & 1 & 1 \\
\hline
\end{tabular}

Fuente: elaboración propia basada en la Estación Meteorológica FADU UAT 2012-2013 de Tampico, Tamaulipas.

Figura 5. Altura solar, solsticios y equinoccio

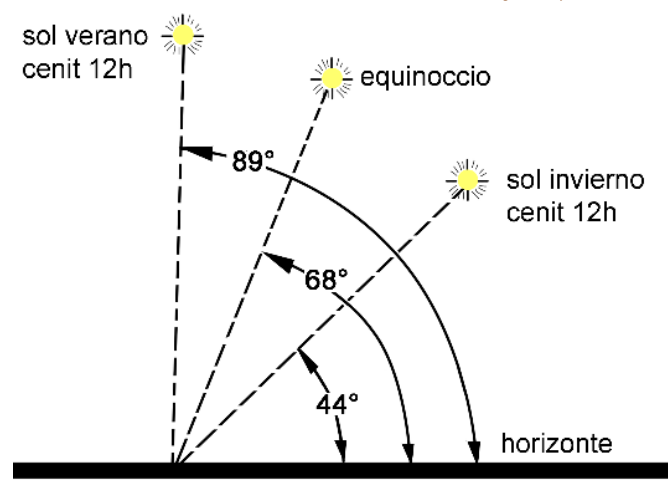

Figura 6. Estereográfico de Tampico

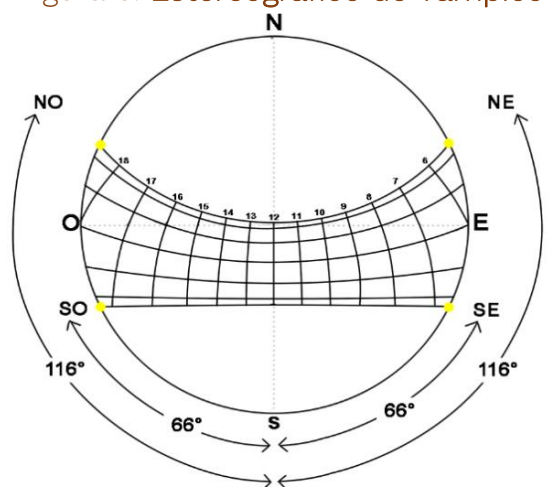

Fuente: elaboración propia, basada en Heliodon. Beckers, B., Masset, L. 2006.

El clima característico de la zona de Tampico, nos permite determinar que, aunque las temperaturas no son muy altas, se tiene una gran la influencia de los cuerpos de agua como reguladores térmicos, y el alto porcentaje de humedad que permanece en la zona es un dato a considerar en el diseño arquitectónico y urbano.

\section{Determinación de zonas de confort permisible, ventilación natural y necesidades de enfriamiento con aire acondicionado}

La sensación de confort térmico está relacionada con las pérdidas y ganancias de energía de una persona en un determinado lugar, para conseguirlo es necesario considerar en el diseño bioclimático la ubicación y orientación de las edificaciones, la vegetación, los materiales de fachadas, suelos y pavimentos, para mejorar el microclima y obtener más horas de confort en los espacios exteriores. 


\subsection{Zonas de confort permisible}

La herramienta informática Comfort Ex, desarrollada por Ochoa, J. M. (1999), se utilizó para hacer un diagnóstico de las zonas de confort permisible en Tampico a partir de los datos climatológicos de 1981-2010. Con esta información los resultados del diagnóstico se muestran en la Figura 7, las recomendaciones de confort para Tampico.

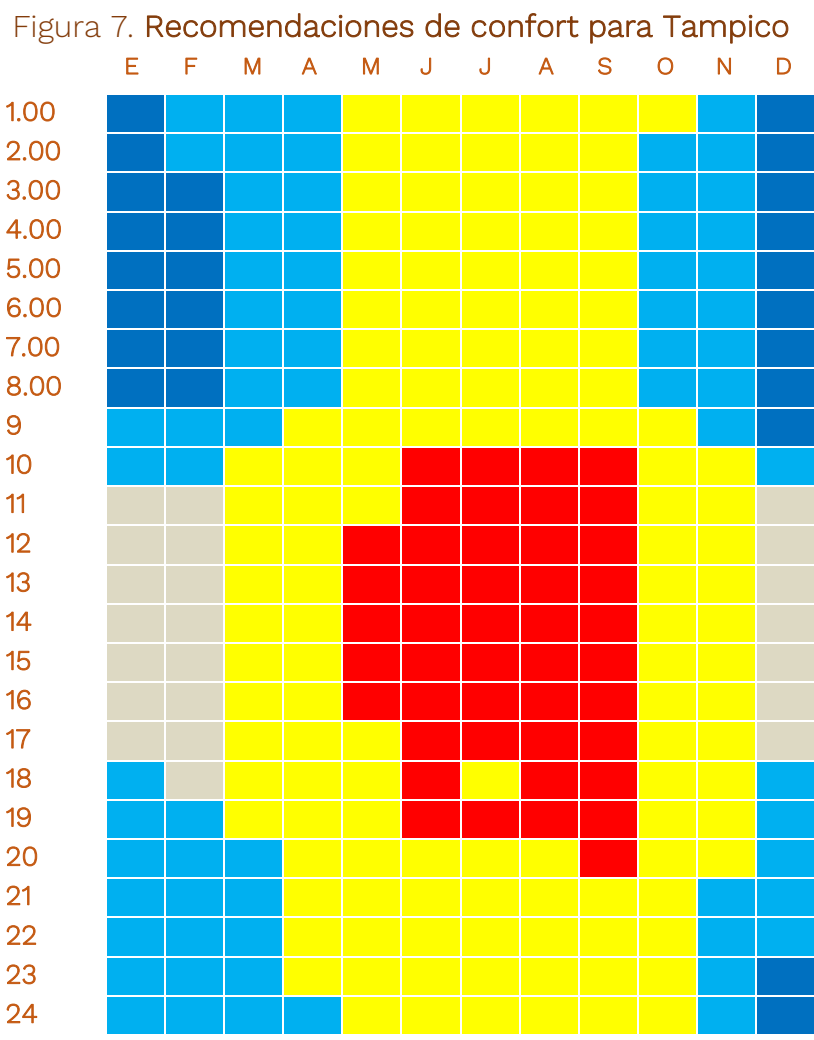

Simbología de los resultados de Comfort Ex
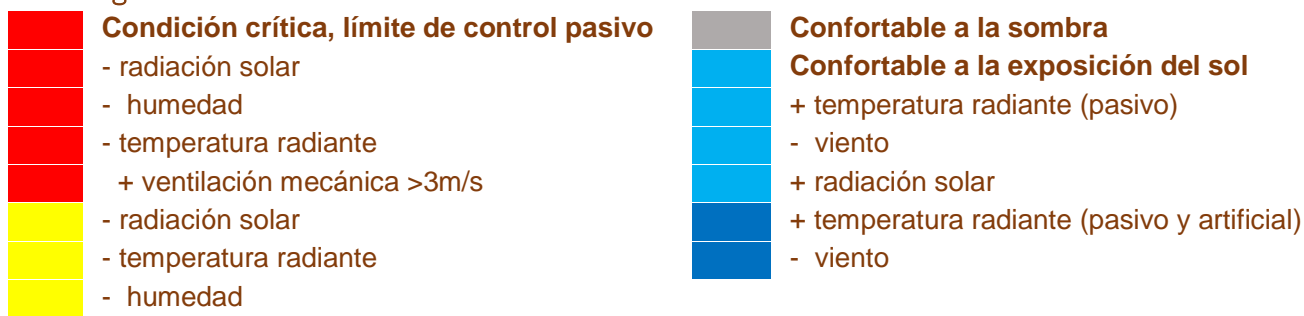

Fuente: elaboración propia, basada en Comfort Ex.

El periodo más largo de disconfort es el cálido, comprende cinco meses, desde mayo hasta septiembre. En el mes de mayo se presenta desde las 12 hasta las 16 horas, en los meses de junio, julio y agosto desde las 10 hasta las 19 horas; el que dura más tiempo es en septiembre, con once horas desde las 10 hasta las 20 horas. Para lograr el confort en los espacios interiores se necesitan sistemas pasivos que reduzcan la radiación solar, la humedad y la temperatura radiante; y como sistemas activos, aire acondicionado o ventilación mecánica con una velocidad mayor a los $3 \mathrm{~m} / \mathrm{s}$. El periodo de disconfort frío comprende tres meses, desde diciembre hasta febrero. En el mes de diciembre se presenta desde las 23 horas hasta las 8 horas, en enero desde la 1 hasta las 8 horas y febrero desde las 3 hasta las 8 horas. Para lograr el confort se necesita, más captación solar, 
temperatura radiante (pasivo y artificial) y menos viento. El periodo de confort, donde no se necesita ninguna actuación, se presenta en los meses de diciembre y enero desde las 11 hasta las 17 horas, y en febrero desde las 11 hasta las 18 horas. Para lograr el confort con sistemas pasivos, se necesitan en los meses de marzo, abril, octubre y noviembre. En marzo y noviembre con menos ventilación desde las 20 hasta las 9 horas, en abril desde las 24 hasta las 8 horas y en octubre desde las 2 hasta las 8 horas. Durante el día se necesita menos radiación solar y menos humedad, en marzo desde las 10 hasta las 19 horas, en abril desde las 9 hasta las 23 horas, en octubre desde las 9 hasta las 1 horas y en noviembre desde las 10 hasta las 20 horas.

Figura 8. Resultados de Comfort Ex en gráfica estereográfica
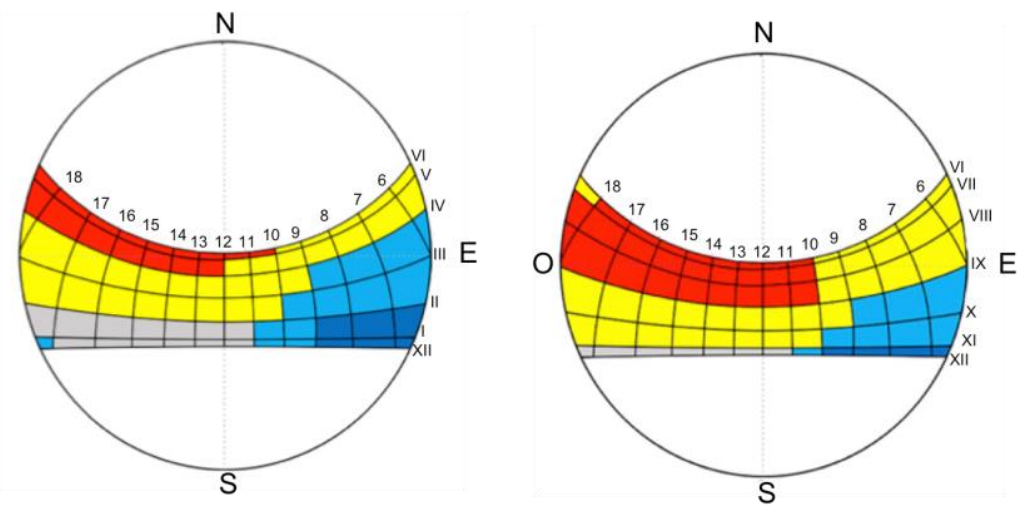

Fuente: elaboración propia, utilizando los softwares Heliodon y Comfort Ex.

Los resultados de Comfort Ex considerados críticos, se dibujaron en la gráfica estereográfica de Tampico (Figura 8) para determinar los meses en disconfort, con sus respectivas horas, altitud y acimut, estos datos se ordenaron en la Tabla 4, esta tabla se dividió en cuatro columnas. La segunda, tercera y cuarta columnas están subdivididas en cuatro: los números en color café obscuro corresponden a disconfort por calor (color amarillo de grafica estereográfica) y en color café claro el disconfort crítico por calor (color rojo de gráfica estereográfica). En la primera columna se colocaron los meses en disconfort de marzo a noviembre. En la segunda columna, las horas que inicia y termina el disconfort. En la tercera columna, se colocó la altitud que tienen los rayos solares cuando inicia y termina el disconfort en calor crítico y el disconfort en calor. La cuarta columna corresponde al acimut y la orientación a la que corresponde.

Tabla 4. Orientaciones en los meses críticos, hora, altitud y acimut

\begin{tabular}{|c|c|c|c|c|c|c|c|c|c|c|c|c|}
\hline Mes & \multicolumn{4}{|c|}{ Hora } & \multicolumn{4}{|c|}{ Altitud } & \multicolumn{4}{|c|}{ Acimut } \\
\hline III & 10 & & & 18.00 & $53^{\circ}$ & & $68^{\circ}$ & 10 & 123SE & & $180 \div S$ & $270 \div 0$ \\
\hline IV & 9 & & & 18.15 & 460 & & $80^{\circ}$ & 10 & 96으 & & $180 \div S$ & $282^{\circ} \mathrm{ONO}$ \\
\hline V & 5.30 & 12 & 12 & 18.30 & 1o & & $88^{\circ}$ & 10 & 68NE & & $180 \div 5$ & $292^{\circ} \mathrm{ONO}$ \\
\hline VI & 5.20 & 10 & 10 & 18.40 & 10 & $62^{\circ}$ & 890 & 10 & $81^{\circ} \mathrm{E}$ & $81^{\circ} \mathrm{E}$ & $180 \div S$ & $296 \div \mathrm{ONO}$ \\
\hline VII & 5.30 & 10 & 10 & 18.00 & 10 & $62^{\circ}$ & $88^{\circ}$ & 8응 & $88^{\circ}=$ & $88^{\circ} \mathrm{E}$ & 180 S & $289^{\circ} \mathrm{ONO}$ \\
\hline VIII & 5.45 & 10 & 10 & 18.15 & 10 & $60 \circ$ & 80 & 10 & $78^{\circ} \mathrm{E}$ & 105을 & $180 \div S$ & $282^{\circ} \mathrm{ONO}$ \\
\hline IX & 6 & 10 & 10 & 18.00 & 10 & $53^{\circ}$ & $68^{\circ}$ & 10 & $90^{\circ} \mathrm{E}$ & $123^{\circ}$ ESE & $180 \div S$ & 27190 \\
\hline$x$ & 9 & & & 17.40 & $34^{\circ}$ & & 560 & 10 & 123을 & & $180 \div 5$ & $257 \div 500$ \\
\hline IX & 10 & & & 17.20 & 380 & & 470 & 10 & 143오 & & $180 \div 5$ & 2470500 \\
\hline
\end{tabular}

Fuente: elaboración propia, utilizando los softwares Heliodon y Comfort Ex.

Se observa en la Tabla 4, la necesidad de mayor protección solar en todas las fachadas en los meses de mayo a septiembre con altura solar desde 89 hasta que se oculta del sol, al Este desde los 60 y del Este-Sureste desde los 53, del Sur desde los 68ㅇ y del Oeste-Noroeste durante todo el día. En mayo de 5.30 a18.30 horas, en junio de 5.20 a 18.40 horas, en julio de, 5.30 a 18 horas agosto de 5.45 a 18.15 y septiembre de 6 a 18 horas. 


\subsection{Ventilación natural y necesidades de enfriamiento con aire acondicionado}

Después de haber analizado con los softwares Comfort Ex y Heliodon, se procedió a utilizar el diagrama psicrométrico, para determinar cuáles serían las actuaciones arquitectónicas, con medios pasivos de control ambiental, para devolver las condiciones a la zona de confort. Para determinar las necesidades de tratamiento del aire en Tampico, se ubicaron en el diagrama los datos de temperatura promedio del aire máximas, medias y mínimas con la humedad relativa de cada mes del Sistema Meteorológico Nacional de Tampico, del periodo 1981-2010 y los mismos datos de la estación meteorológica de la FADU UAT 2012-2013.

Figura 9. Diagrama psicrométrico

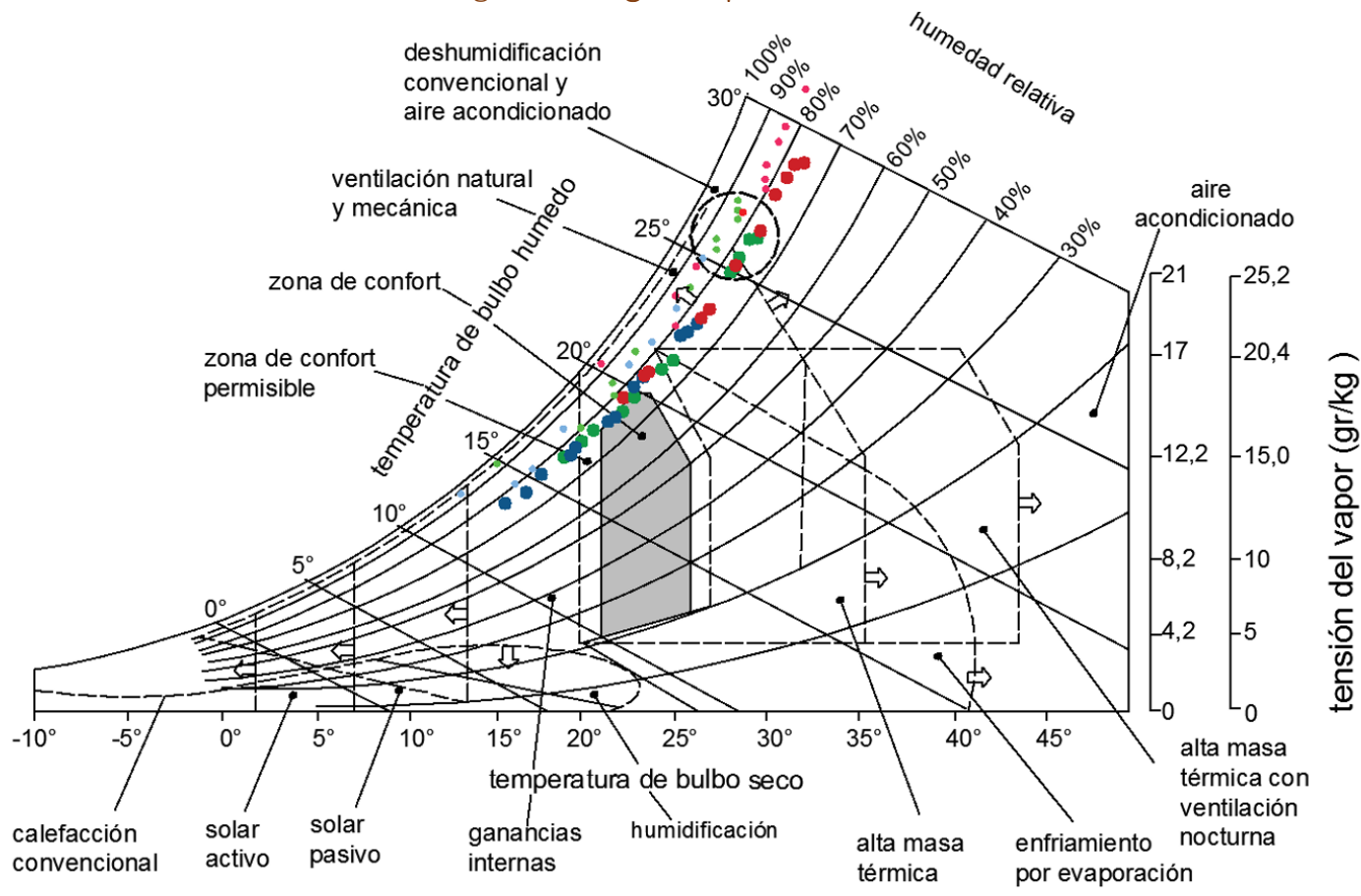

Simbología

Temperaturas promedio
y humedad relativa

Máxima

Media

Mínima
Sistema meteorológico Nacional Tampico 1981-2010
Estación meteorológica FADU UAT 2012-2013

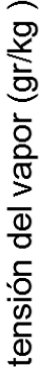

Fuente: elaboración propia basada en Givoni, 1976.

En la Figura 9, se observa que la temperatura promedio del periodo 1981 a 2010 se mantenía en zona de confort permisible los meses de diciembre, enero y febrero, en zona de confort los meses marzo y noviembre, con ventilación natural y mecánica se lograba el confort en los meses de abril, mayo y octubre y solo los meses junio, julio, agosto y septiembre con deshumidificación convencional y aire acondicionado. En los años del 2012 y 2013 se observan los seis meses (mayo, junio, julio, agosto, septiembre y octubre) que se necesita deshumidificación convencional y aire acondicionado para lograr el confort (Figura 10). 
Figura 10. Ampliación de zona de deshumidificación convencional y aire acondicionado del diagrama psicrométrico de Givoni

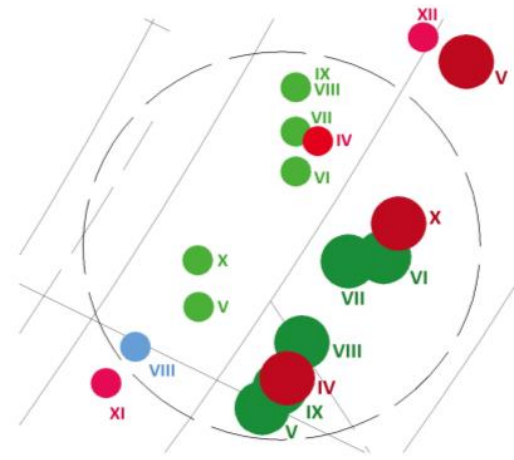

Fuente: elaboración propia, 2019.

La ventilación natural es el sistema de refrigeración más adecuado, aprovechando los vientos y las brisas, facilitando las pedidas de calor por convección y evaporación, reduciendo el disconfort por calor, debido al alto grado de humedad relativa. Las losas y muros de las edificaciones deberán ser de materiales ligeros de escasa inercia térmica. Los techos altos con aberturas en la parte superior de las fachadas para que el aire caliente suba y salga, también pueden utilizarse bóvedas y /o chimeneas para ventilar. Es necesario utilizar dispositivos de sombra para las ventanas o huecos con cristal. Los dispositivos al exterior como toldos, persianas o lamas, que son flexibles son una buena opción a los cambios estacionales de primavera, verano y otoño. Las pantallas interpuestas entre la fachada soleada en verano, pueden ser fijas y variables, teniendo en cuenta la trayectoria del sol (acimut y altitud).

\subsection{Estrategias generales de diseño}

Los principales factores que influyen en el microclima de un lugar los retoma Yáñez (2008): 1. El soleamiento y vientos dominantes en verano e invierno; 2. Proximidad a zonas de agua; 3. Proximidad a zonas verdes; 4. El relieve y 5. Tipo de suelo o pavimentación. Los resultados en el diagrama psicométrico muestran que el periodo de disconfort en calor es de nueve meses de marzo a noviembre.

\subsection{Análisis y discusión de resultados}

La ventilación natural, se recomienda en nueve meses, de marzo a noviembre como se muestra en la tabla 5. Las construcciones deben estar separadas para que fluya el viento y considerar las distintas formas, su orientación y relación de unos con otros. Las ventanas de las edificaciones preferentemente deben estar a los vientos reinantes: al Este y Sureste para asegurar el movimiento del aire con una ventilación cruzada y con aberturas al Norte, Noreste y Suroeste; de diferentes tamaños, y más grande la de salida, para obtener una mayor velocidad al interior. En los estudios que realiza Gonzalo (2004) las ventanas oblicuas presentan mayores velocidades al interior, con ventanas de $2 / 3$ de la fachada de entrada y $3 / 3$ de salida.

La ventilación mecánica y deshumidificación, se propone utilizar ventiladores de techo o pedestal en los meses de mayo a octubre, para disminuir la humedad, que durante el día es mayor al 85\% y es necesario el movimiento del aire en el interior de las habitaciones, sobre todo durante la noche cuando la velocidad del viento es baja. El sombreamiento en huecos, se sugiere en todas las orientaciones. Las aberturas deberán contar con protecciones solares horizontales y/o verticales que se puedan manipular de acuerdo a la trayectoria solar. Se deben evitar aberturas al cenit, ya que la radiación de onda larga que ingresa aumenta el disconfort por calor al interior de las edificaciones. 
La captación solar, se recomienda en los meses más fríos de diciembre, enero y febrero; y evitarla de abril a octubre propiciando la ventilación natural. Se recomienda orientar los edificios sobre el eje Este- Oeste donde sus fachadas más largas se ubiquen al Norte y Sur, para reducir la exposición al sol, y deberán estar protegidas de la radiación directa y difusa, y de la lluvia.

Tabla 5. Estrategias generales de diseño con base en Comfort Ex

\begin{tabular}{|c|c|c|c|c|c|c|c|c|c|c|c|c|c|}
\hline Estrategias & $\mathrm{E}$ & $\mathrm{F}$ & M & A & M & J & $\mathrm{J}$ & A & S & 0 & $\mathrm{~N}$ & D & No. de meses \\
\hline Ventilación natural & & & $x$ & $x$ & $x$ & $x$ & $x$ & $x$ & $x$ & $x$ & $x$ & & 9 \\
\hline Ventilación mecánica y deshumidificación & & & & & $x$ & $x$ & $x$ & $x$ & $x$ & $x$ & & & 6 \\
\hline Sombreamiento huecos & & & & $x$ & $x$ & $x$ & $x$ & $x$ & $x$ & $x$ & & & 7 \\
\hline Radiación solar & $x$ & $x$ & & & & & & & & & & $x$ & 3 \\
\hline
\end{tabular}

Fuente: elaboración propia.

\section{Evaluación microclimática del multifamiliar}

El conjunto habitacional Ing. Alejandro Prieto es único en la Ciudad de Tampico, Tamaulipas, México; construido en los años 50, para obreros de FOVISSTE (Loredo 2018); se ubica en la colonia Otomí, al Sur de la ciudad de Tampico (Figura 11); colinda al Norte y Este con la Colonia Vergel, al Sur con la Colonia Benito Juárez y al Oeste con la Petrolera. En dirección Este a $7 \mathrm{~km}$ se localiza el Golfo de México, al Sur a $2.8 \mathrm{~km}$ el río Pánuco, al Sureste a $0.8 \mathrm{~km}$ la laguna del Carpintero, y al Oeste a 0.9 $\mathrm{km}$ la laguna del Chairel.

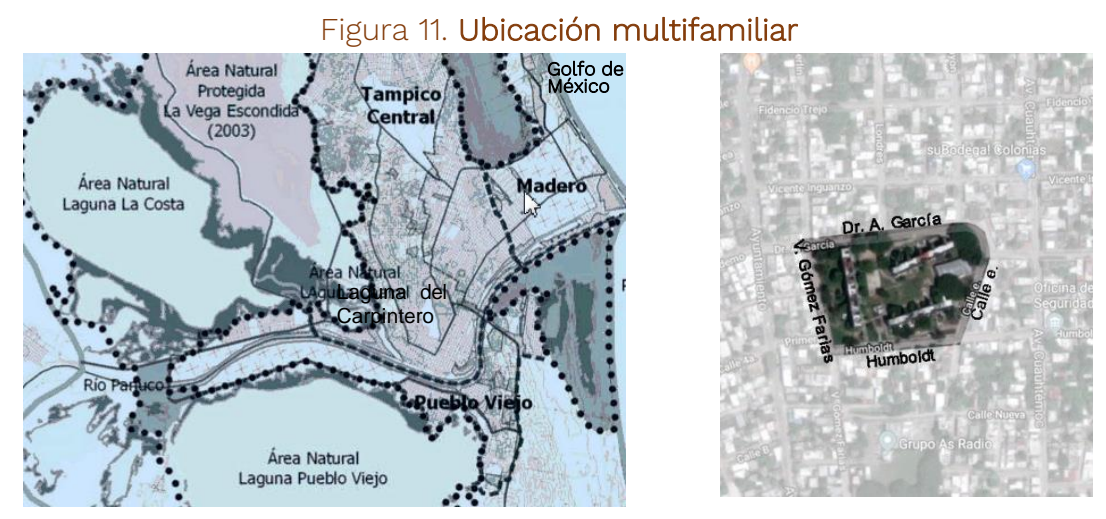

Fuente: Proyecto Integración, elaboración basada en Google Earth.

Los tres edificios de viviendas ocupan una manzana de $22457.68 \mathrm{~m}^{2}$, cada edificio consta de cinco niveles. El edificio A tiene 60 viviendas, doce por nivel; el B y C tienen 50 cada uno, diez por nivel; ocupan un $13 \%$ del total de área lotificada. En el mismo lote se encuentra área comercial que ocupa $5 \%$ de la superficie y un $82 \%$ de áreas verdes, con canchas de básquetbol y circulaciones peatonales (Figura 12).

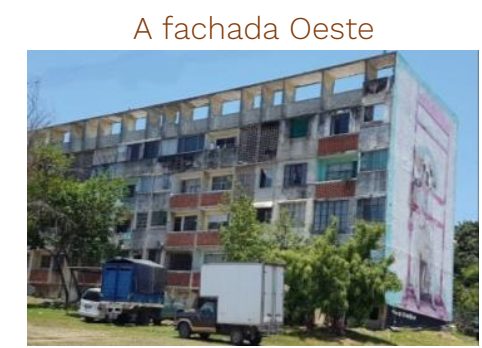

Figura 12. Edifícios A, B, C

$$
\text { B fachada Sureste }
$$

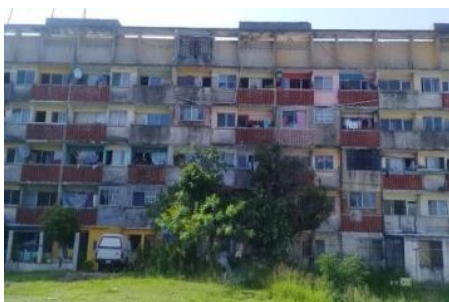

C fachada Noroeste

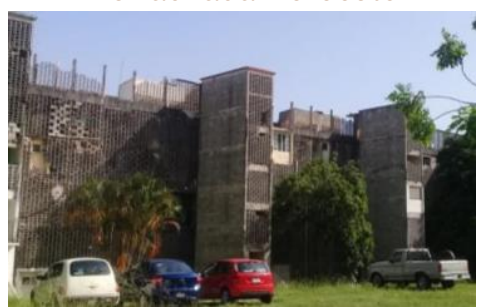

Fuente: elaboración propia. 


\subsection{Estudio de sombras y ángulos solares con Heliodon}

Las imágenes de la Figura 13, corresponden al 23 de mayo, (mes crítico en disconfort de calor); se aprecia el desplazamiento de las sombras de 6 a 18 hora solar. La fachada que recibe más horas de radiación solar es la Noroeste del edificio A, con 8 horas y las de menos son todas las fachadas del edificio C con 6 horas ya que recibe sombra del edificio A y B.

Figura 13. Recorrido del sol en verano, de 6 a 18 horas

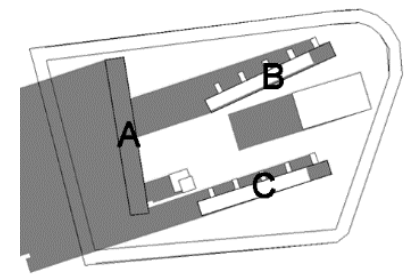

6

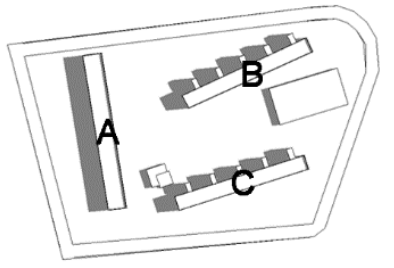

9

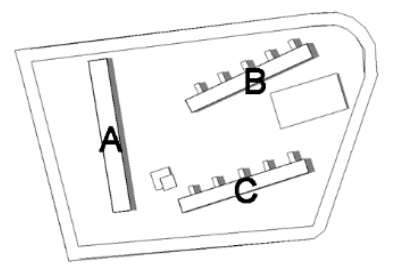

13

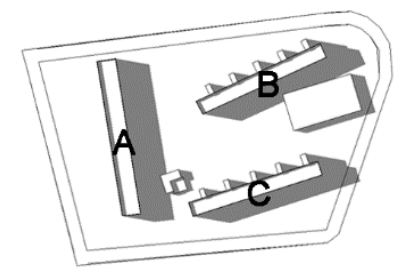

16

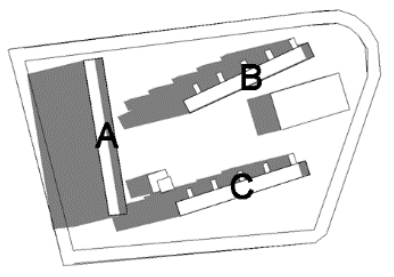

7

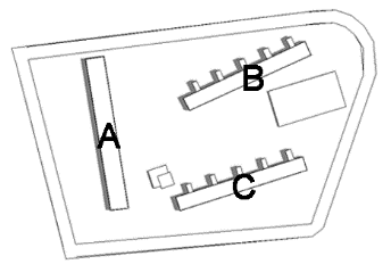

11

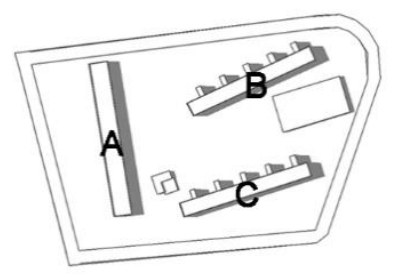

14

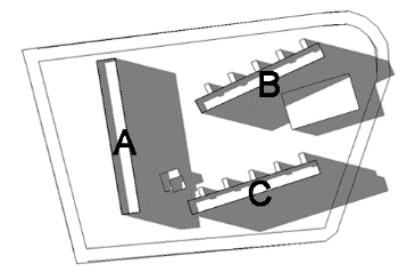

17

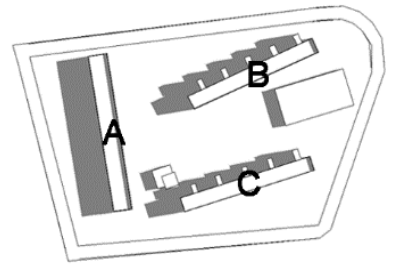

8

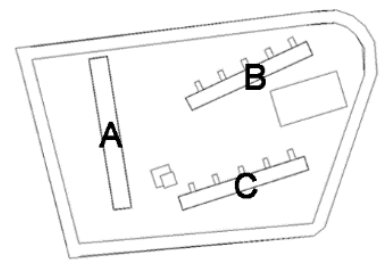

12

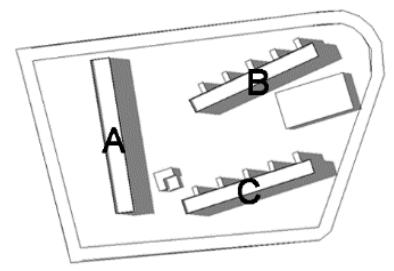

15

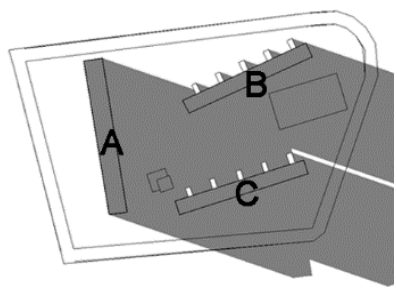

18

Fuente: elaboración propia.

Durante la mañana recibe la radiación solar directa en la fachada Este, permanece en sombra la fachada Oeste desde las 12 a las 18 horas, la altura de los árboles que varían de 3.4 a $16 \mathrm{~m}$ de altura y su fronda de 5 a 15m, su separación de los árboles más altos es de 8 a 12m de las fachadas, son los que generaron sombra durante las horas críticas. Como se observa en la Figura 14.

Durante la tarde recibe la radiación solar directa en las fachadas Noroeste, permanece en sombra las fachadas Suroeste. Las diferencias entre los edificios B y C, es, que el edificio C, recibe durante la tarde en la fachada Noroeste sombras del edificio A, desde las 17 horas y del edifico B a partir de las 18 horas. Como se observa en la Figura 15. 
Figura 14. Corte edificio A. Inclinación de los rayos del sol fachada Oeste 12 a 18 horas y fachada Este 6 a 11 horas, del 23 de mayo

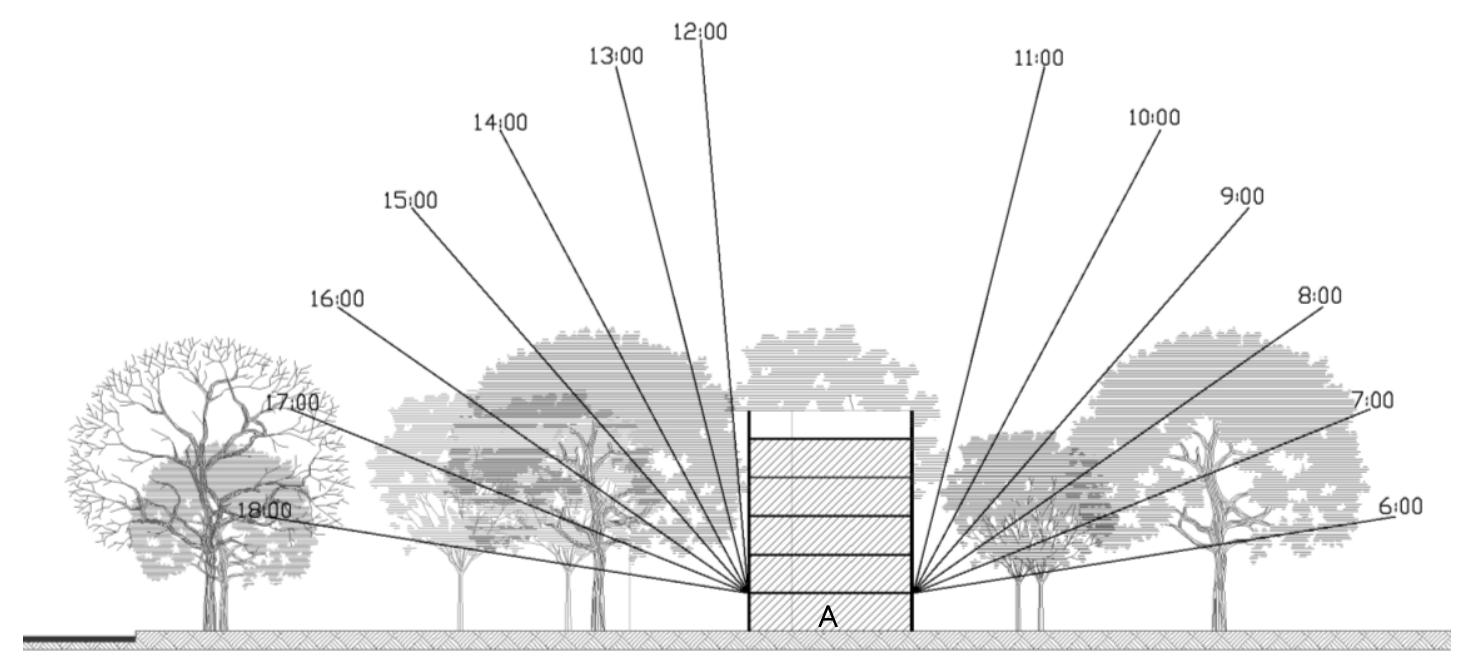

Fuente: elaboración propia.

Figura 15. Corte edificios C y B. Inclinación de los rayos del sol en la fachada Sureste de 13 a 18 horas, del 23 de mayo

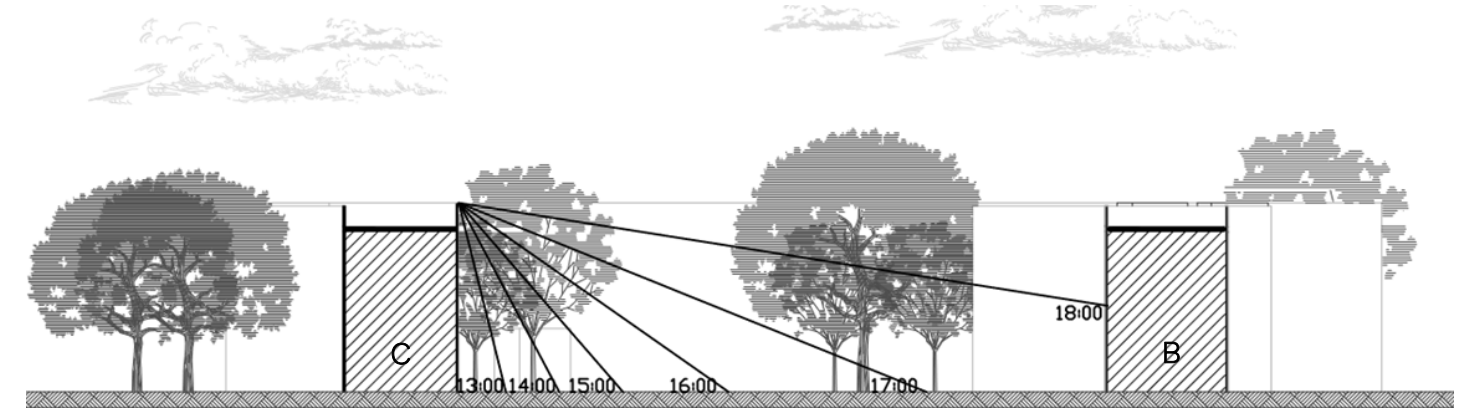

Fuente: elaboración propia.

Durante la mañana recibe la radiación solar directa en las fachadas Noreste y Sureste, permanece en sombra las fachadas Noroeste y Suroeste. Las diferencias entre los edificios B y C, es, que el edificio $\mathrm{C}$, recibe durante la tarde en la fachada Sureste recibe de 8 a 13 horas las sombras de los árboles, cuya altura varía de 6 a $12 \mathrm{~m}$ el diámetro de su fronda de 8 a12 m, con una separación de la fachada de 6 a $18 \mathrm{~m}$. Como se observa en la Figura 16.

Figura 16. Corte edificios C y B. Inclinación de los rayos del sol en la fachada Noroeste de 6 a 11 horas, del 23 de mayo

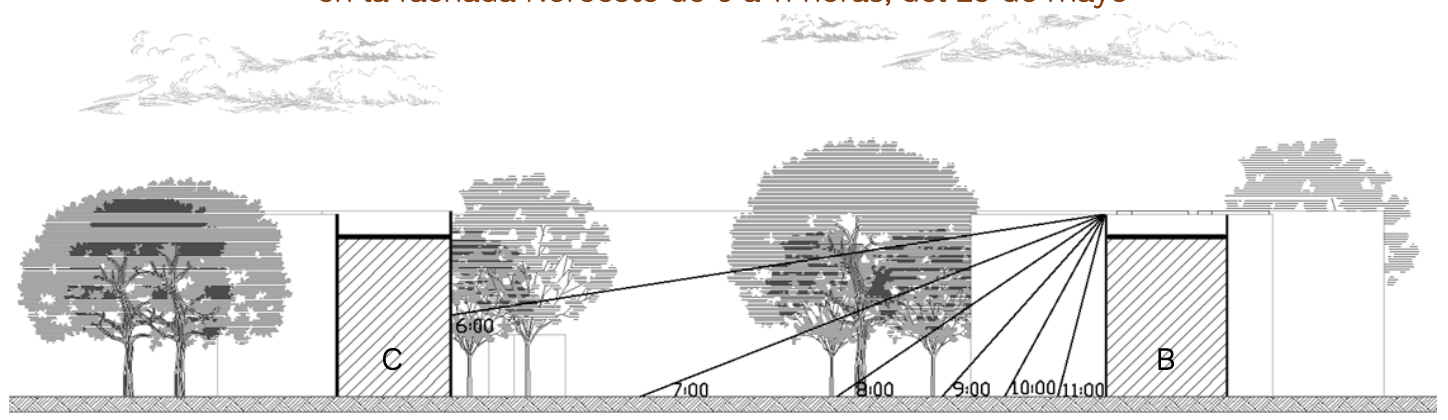

Fuente: elaboración propia. 


\section{Análisis de fachadas y vegetación de los tres edificios A, B, y C del Conjunto Habitacional Ing. Prieto, con temperatura del aire, de superficie y estudio de vegetación existente}

Para el registro de la información, se diseñó una ficha de datos donde se capturaron las mediciones de acuerdo a los recorridos establecidos, los cuales iniciaron en el edificio A en el orden de las siguientes fachadas Oeste, Sur, Este y Norte, se continuó con el edificio C con las fachadas Noroeste, Noreste, Sureste y Suroeste y se terminó en el edificio B siguiendo las fachadas Noroeste, Noreste, Sureste y Suroeste.

Las mediciones se realizaron el 23 de mayo del 2018, a las 8, 9, 10, 11, 12 13, 14 15, 16 y 17 horas. El recorrido frente a las fachadas de los edificios A, B y C, duraba aproximadamente cincuenta minutos, al finalizar, se tomaba un receso de diez minutos e iniciaba el siguiente registro.

Los instrumentos para las mediciones fueron la estación meteorológica manual Krestel 4000 Pocket Weather Tracker y la cámara térmica Fluke Ti25. La estación meteorológica se utilizó a una altura de $1.30 \mathrm{~m}$. y a una distancia de la fachada aproximadamente de un metro y la cámara térmica se colocó a la altura del observador de $1.30 \mathrm{~m}$. y a una distancia aproximada de la fachada de $0.30 \mathrm{~m}$. Al llegar al punto de medición, con la estación meteorológica, primero se dejaban pasar veinte segundos para iniciar el registro de la mayor y menor temperatura del aire en un lapso de 30 a 60 segundos para posteriormente anotar el promedio y posteriormente con la cámara térmica se tomaba la temperatura superficial, en la cual la medición era en el mismo instante en que se tomaba la imagen.

\subsection{Análisis de temperaturas del aire y temperaturas de las superficies} de las fachadas de los edificios $A, B$ y $C$

En el edificio A la fachada Norte presentó el mayor promedio de temperaturas del aire (Ta) 30.3드 y de superficie (Ts) 33으. En orden descendente fue la Oeste con Ta 30.2으 y Ts 32.8으. El valor intermedio fue la Sur con Ta $29.8^{\circ} \mathrm{C}$ y Ts $31.2^{\circ} \mathrm{C}$ y el menor fue en la Este con Ta 29.6 ㄷ $\mathrm{y}$ Ts $31.1{ }^{\circ} \mathrm{C}$. Como se observa en la Figura 17.

Figura 17. Edificio A. Gráficas temperaturas del aire y temperaturas de superficie fachadas Norte, Sur, Este, y Oeste
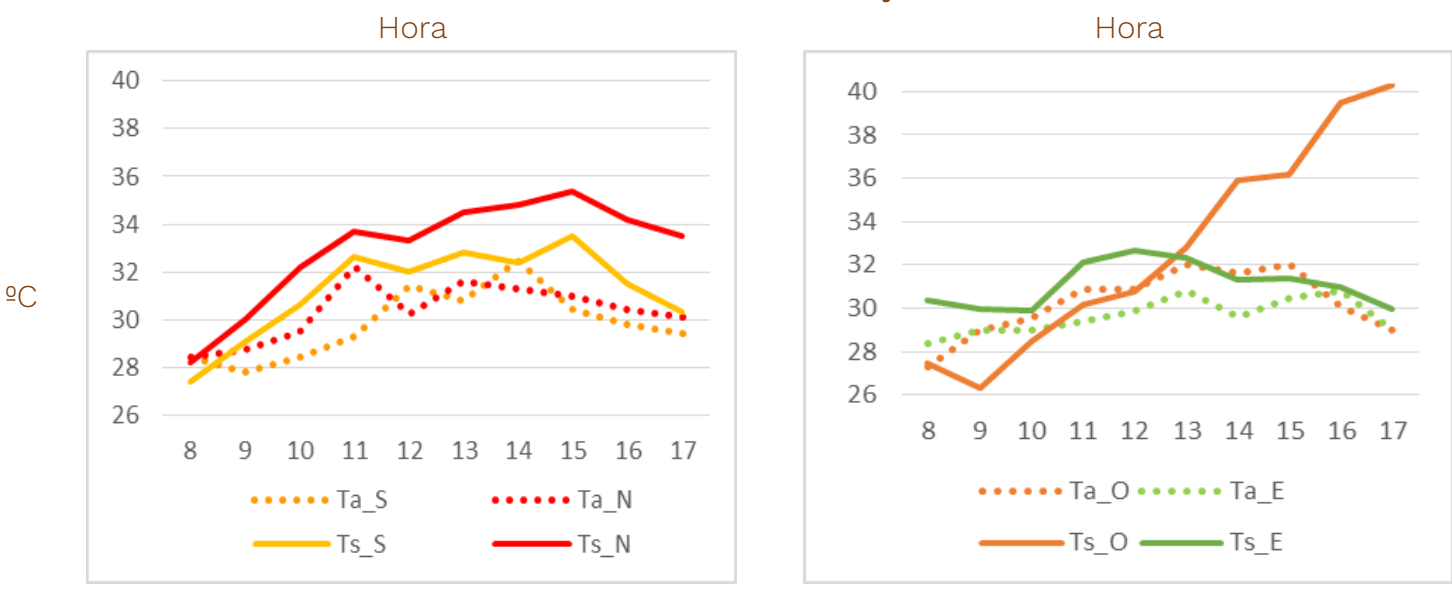

Fuente: elaboración propia. 
En el edificio B la fachada Noroeste presentó el mayor promedio de Ta con 31.2º $\mathrm{C}$, siguió la Sureste con Ta 30.3으 y Ts 31.2으. En orden descendente fue la Suroeste con Ta $29.8^{\circ} \mathrm{C}$ y la Noroeste con Ts 30.5ㄷ․ La fachada Noreste mostró el menor valor con Ta 29.7으 y Ts 30.4ํㅡ. Como se observa en la Figura 18.

Figura 18. Edificio B. Gráficas temperaturas del aire y temperaturas de superficie, fachadas Noreste, Suroeste, Noroeste y Sureste

Hora

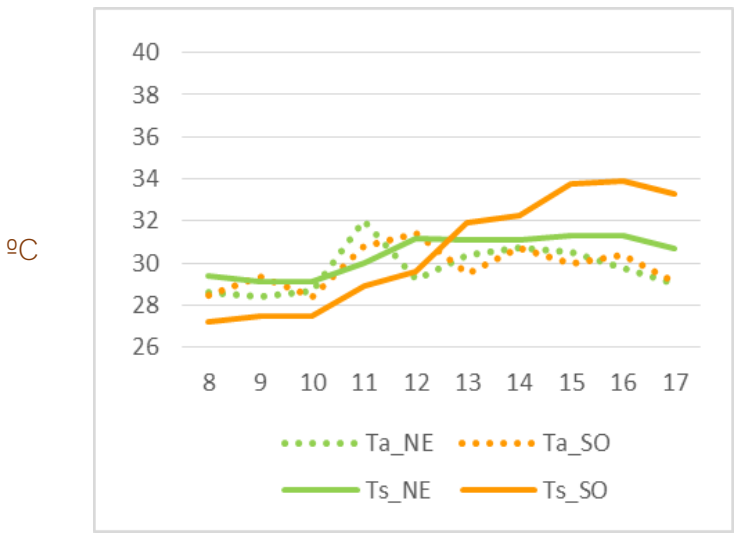

Hora

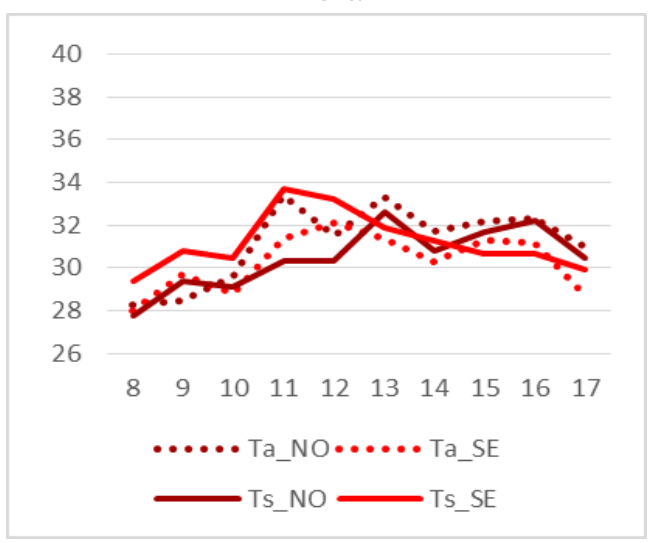

Fuente: elaboración propia.

En el edificio C la fachada Noroeste presentó el mayor promedio de Ta con 31.19- , siguió la Suroeste con Ta 30.4으 y Ts 34.3ㄷ․ En orden descendente fue la Noreste con Ts 31.7으. La fachada de valor intermedio fue la Sureste con Ta 29.9ㅇ y Ts 30.6으. Los menores valores fueron la Noreste con Ta 29.4ํㅡ y la Noroeste con Ts 30.3ํ․ Como se observa en la Figura 19.

Figura 19. Edificio C. Gráficas temperaturas del aire y temperaturas de superficie, fachadas noreste, suroeste, noroeste y sureste Hora

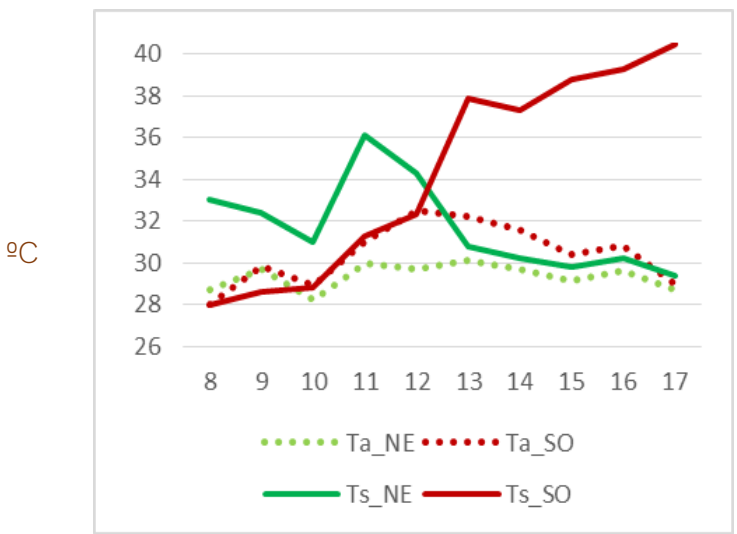

Fuente: elaboración propia.
Hora

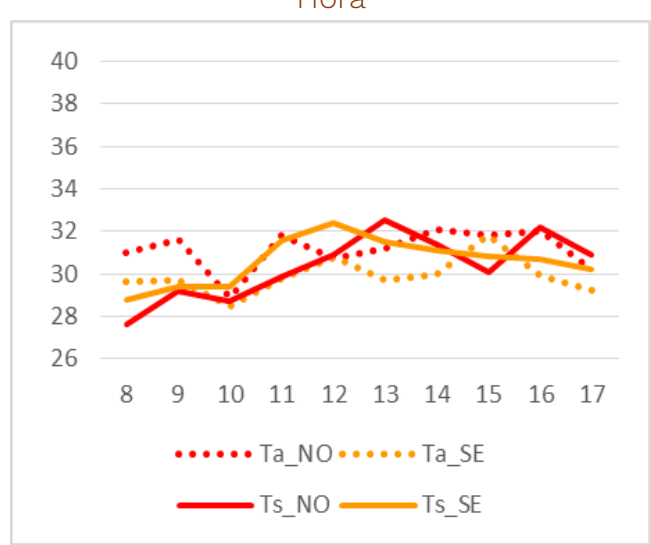

5.2 Análisis de temperaturas del aire y superficial de árboles frente a fachadas Oeste edificio A, Noreste edificio B y Suroeste edificio C

Corburn (2009), demuestra que el arbolado urbano reduce las temperaturas. En un estudio entre julio y octubre del 2005 registraron que se redujo de $2^{\circ} \mathrm{C}$ a $6^{\circ} \mathrm{C}$ y de $2^{\circ} \mathrm{C}$ a $9^{\circ} \mathrm{C}$ en la ciudad de 
Crown Heights, Brooklyn, acelera la refrigeración en la noche, aumentan la evapotranspiración y refrigeración por evaporación.

El 23 de mayo del 2018 se realizó el levantamiento de campo de temperaturas del aire bajo árboles y temperatura superficial del tronco y hojas de árboles frente a las fachadas Oeste del edificio A, Noroeste edificio B y Suroeste edifico C (Figura 20); cada dos horas a partir de las 8 hasta las 16 horas. Para la medición de temperatura superficial se utilizó la cámara térmica Fluke Ti25 y para temperatura del aire la estación meteorológica manual Krestel, en la Figura 21 se muestran los resultados.

Figura 20. Ubicación en planta y fotografías frente a fachadas Oeste edifico A, Noroeste edificio B y Suroeste edificio C
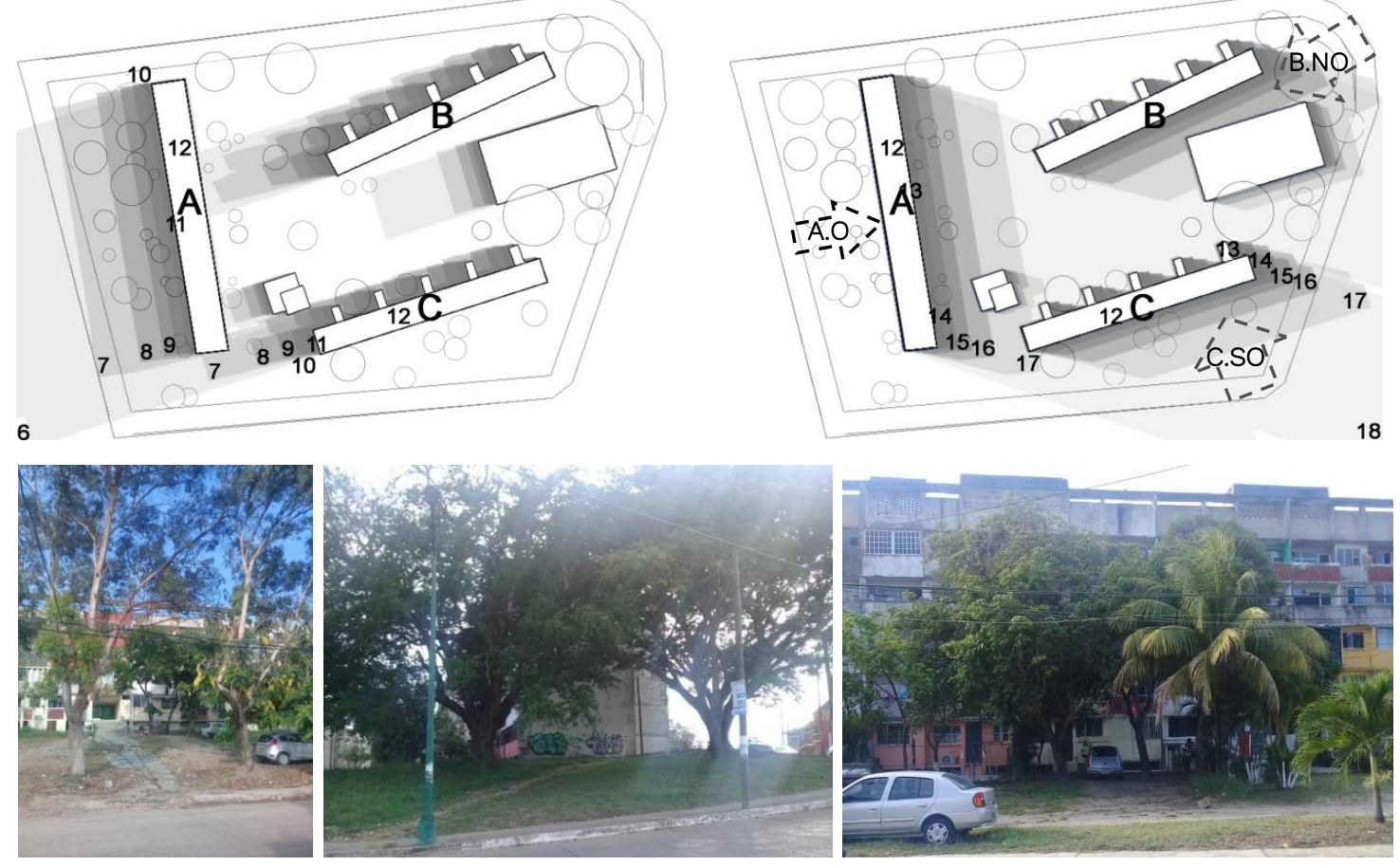

Fuente: elaboración propia.

Figura 21. Gráfica de temperaturas del aire y superficial de árboles frente fachadas Oeste edificio A, Noroeste edificio B y Suroeste edificio C

으

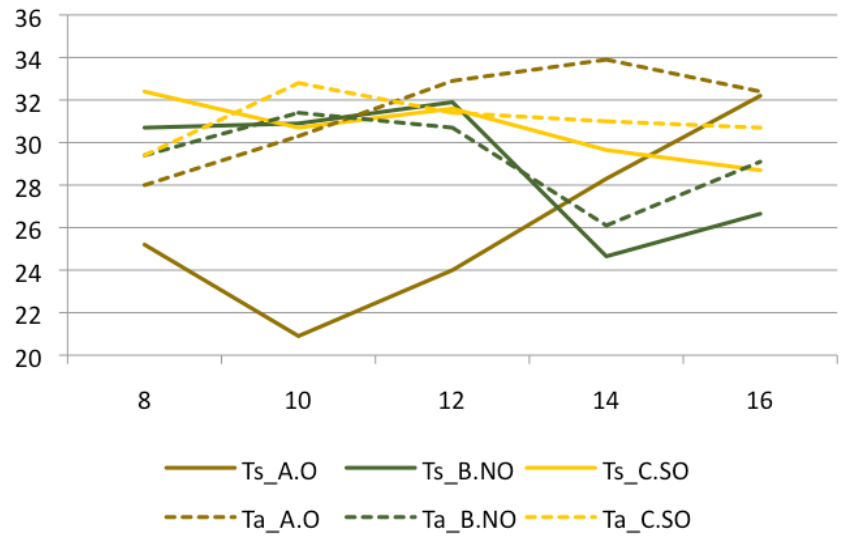

Fuente: elaboración propia. 
En el edifico A, la vegetación frente a la fachada Oeste, presentó el más alto valor de temperatura del aire Ta_A.O. En el edifico C, frente a la fachada Suroeste presentó el mayor promedio de temperatura superficial Ts_C.SO. Los que presentaron los más bajos valores, fueron el edificio A frente a la fachada Oeste la temperatura superficial de la vegetación Ts_A.O y frente al edifico B, la fachada Noroeste la temperatura del aire Ta_B.NO. Se destaca la baja Ts de la vegetación durante la mañana frente a edifico A fachada Oeste donde recibe sombra del edificio durante 5 horas.

En la Tabla 6, se muestra el edificio A como el más crítico, todas sus fachadas presentaron la temperatura superficial superior a los $31^{\circ} \mathrm{C}$. Se destaca la fachada Oeste por presentar la mayor masa vegetal con $9227 \mathrm{~m}^{3}$ con una temperatura superficial de $32.8^{\circ} \mathrm{C}$ y una temperatura del aire de $30.2^{\circ} \mathrm{C}$. La diferencia de estas dos temperaturas se debe a la sombra que produce el Edificio $\mathrm{A}$ desde las 6 hasta las 11 horas.

Tabla 6. Resumen. Temperaturas promedio del aire y superficie; volumen de vegetación frente a fachadas de Edificios A, B y C

\begin{tabular}{|c|c|c|c|c|c|c|c|c|c|c|c|}
\hline $\begin{array}{c}\text { Edificio } \\
\text { A }\end{array}$ & $\mathrm{Ta}$ & Ts & $\begin{array}{l}\text { Veg } \\
\mathrm{m}^{3}\end{array}$ & $\begin{array}{c}\text { Edificio } \\
\text { B }\end{array}$ & $\mathrm{Ta}$ & Ts & $\begin{array}{l}\text { Veg } \\
\mathrm{m}^{3}\end{array}$ & $\begin{array}{c}\text { Edificio } \\
\text { C }\end{array}$ & $\mathrm{Ta}$ & Ts & $\begin{array}{l}\text { veg } \\
\mathrm{m}^{3}\end{array}$ \\
\hline $\mathrm{N}$ & 30.3 & 33.0 & 0 & NO & 31.2 & 30.5 & 854 & NO & 31.1 & 30.3 & 6738 \\
\hline$S$ & 29.8 & 31.2 & 0 & $\mathrm{NE}$ & 29.7 & 30.4 & 7304 & $\mathrm{NE}$ & 29.6 & 31.7 & 0 \\
\hline$E$ & 29.6 & 31.1 & 2161 & SE & 30.3 & 31.2 & 139 & SE & 29.9 & 30.6 & 2347 \\
\hline 0 & 30.2 & 32.8 & 9227 & SO & 29.8 & 30.6 & 0 & SO & 30.4 & 34.3 & 0 \\
\hline Total & 30.0 & 32.0 & 11388 & & 30.3 & 30.7 & 8297 & & 30.2 & 31.7 & 9085 \\
\hline
\end{tabular}

Fuente: elaboración propia.

El edificio B presentó el mejor comportamiento con el promedio más bajo de temperaturas de superficie. Frente a la fachada Noreste la vegetación con un volumen de $7304 \mathrm{~m}^{3}$ no tiene una reducción significativa sobre la temperatura del aire, esto se observa con la diferencia de $0.7^{\circ} \mathrm{C}$ entre Ts y Ta.

En el edificio C se presenta la fachada Suroeste como la más crítica con una Ts de $34.3{ }^{\circ} \mathrm{C}$, se observa que, aunque no existe vegetación frente a esta fachada la temperatura del aire está con una diferencia de $4^{\circ} \mathrm{C}$ menor. Esto nos demuestra que la vegetación no tiene una mayor influencia sobre la temperatura del aire.

\subsection{Análisis flujo de viento alrededor de edificios, árboles y calles}

El movimiento del aire en los espacios exteriores no modifica la temperatura, pero provoca sensación de frescor, sobre todo a la sombra, debido a la pérdida de calor por convección y aumento de la evapotranspiración. Para cada $0.3 \mathrm{~m} / \mathrm{s}$ de velocidad equivale al descenso de $1^{\circ} \mathrm{C}$ en la sensación térmica de una persona.

\section{- Velocidad del viento de 8 a 10 horas en los edificios A, B y C en la escala de Beaufort}

En el edificio A, la velocidad promedio fluctuó, de viento en calma a brisa leve. Las velocidades más bajas se presentaron en la fachada Norte con viento en calma y brisa muy suave; y las más altas y constantes en la fachada Sur con brisa muy suave. En el edificio B, la velocidad promedio fluctuó, de viento en calma a brisa muy suave. Las velocidades más bajas, se registraron en la fachada Noroeste, con viento en calma y brisa muy suave. Las más altas, se registraron en la fachada Sureste, con una brisa muy suave. En el edificio C, la velocidad promedio fluctuó, de viento en calma a brisa leve. Las velocidades más bajas se presentaron en la fachada Noroeste, con viento en clama y brisa muy suave, y las más altas y constantes, fueron en las fachadas Suroeste con brisa muy suave y brisa leve. 
- Velocidad del viento de las 11 a 13 horas en los edificios A, B y C en la escala de Beaufort

En el edificio A, la velocidad promedio fluctuó, de viento en calma a brisa leve. Las velocidades más bajas se registraron en la fachada Norte, con viento en calma y brisa muy suave, y las más altas en la fachada Sur, con brisa muy suave y brisa leve. En el edificio B, la velocidad fluctuó, de viento en calma a brisa suave. Las velocidades más bajas se presentaron frente a la fachada Sureste, con viento en calma y las más altas en la fachada Suroeste, con brisa muy suave y brisa suave. En el edificio C, la velocidad fluctuó, de viento en calma a brisa leve. Las velocidades más bajas se registraron en la fachada Suroeste con viento en calma y brisa muy suave, y las más altas se registraron en la fachada Noreste con brisa muy suave y brisa leve.

- Velocidad del viento de las 14 a 17 horas en los edificios A, B y C en la escala de Beaufort

En el edificio A, la velocidad promedio fluctuó, de viento en calma a brisa leve. Las velocidades más bajas se registraron en la fachada Oeste, con viento en calma, y las más altas se registraron en la fachada Este con brisa leve y brisa suave. En el edificio B, la velocidad fluctuó, de viento en calma a brisa suave. Las velocidades más bajas se registraron en la fachada Noroeste, con viento en calma y brisa muy suave; las más altas se registraron en la fachada Suroeste, fluctuaron entre brisa muy suave, brisa leve y brisa suave. En el edificio C, la velocidad fluctuó, de viento en calma a brisa suave. Las velocidades más bajas se registraron en la fachada Noroeste, con viento en calma y brisa muy suave; las más altas se registraron en la fachada Noreste, entre brisa leve y brisa muy suave.

En resumen, el flujo de viento se observa en la figura 22, con una dirección constante del Sureste durante el día. Las velocidades más bajas se presentan en las fachadas Norte y Noroeste; se destacan con flechas más grandes y oscuras, las velocidades más altas, con dirección Sureste desde las 11 hasta las 17 horas.

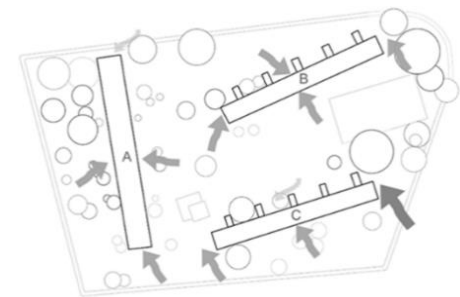

8

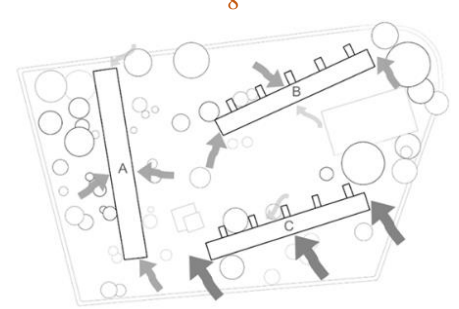

11

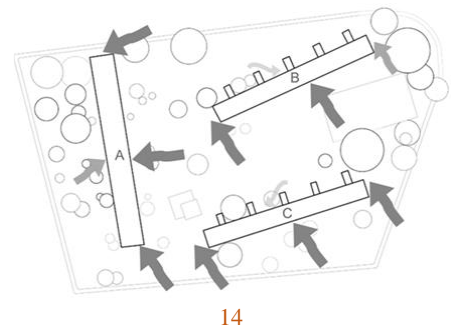

14

Figura 22. Flujo de viento

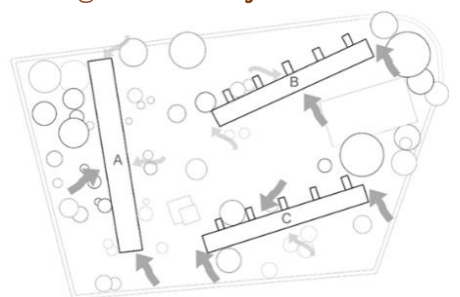

9

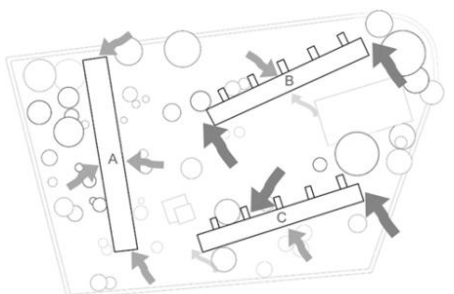

12

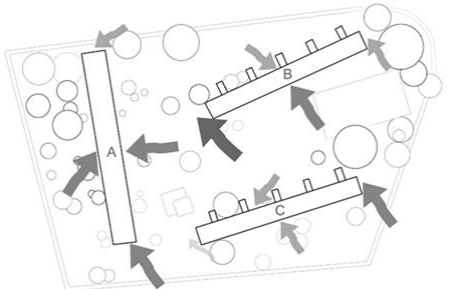

15

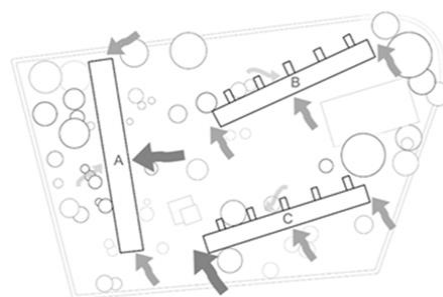

10

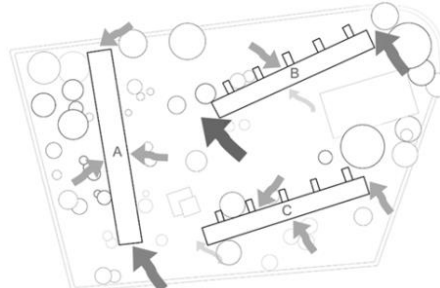

13

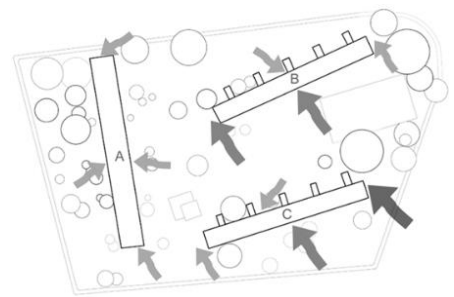

17

Fuente: elaboración propia. 


\section{Resultado del análisis}

El edificio A, se destacó por ser el más crítico, sus fachadas Norte y Oeste presentaron los mayores valores de temperaturas del aire y temperatura de superficie. Posteriormente de los edificios B y C, las fachadas Noroeste fueron las más desfavorecidas en el valor de temperatura del aire, y la fachada Suroeste en la temperatura superficial. Se destaca la poca o nula influencia de la arborización sobre la temperatura del aire. Y la necesidad de tomar en cuenta en el diseño de los edificios el flujo del viento ya que la velocidad alrededor de los edificios a partir de las 13 horas fue de 3.3 a $4.1 \mathrm{~m} / \mathrm{s}$.

El edificio A, de cinco niveles con una altura de $15 \mathrm{~m}$, con una orientación Oeste-Este; recibe sombra durante la mañana, en la fachada Oeste hasta las 11.59 horas; las horas críticas se presentan de 12 a 19 horas, cuando se oculta el sol. Se necesitan protecciones solares en toda la fachada, para evitar el sol en los ángulos solares desde 89a a 0‥ Las protecciones que se pueden utilizar son muros dobles con celosías para ventilar la fachada, o parasoles verticales $u$ horizontales para excluir la radiación solar.

La vegetación en el edificio A, presenta grandes árboles en el lado izquierdo de la fachada Oeste, con una transmisividad que varía de 50, 30 y $15 \%$, algunas partes de la fachada no tienen árboles frente a ella, se recomienda aumentar el grupo de árboles grandes con una transmisividad del $15 \%$.

El edificio B, de cinco niveles con una altura de $15 \mathrm{~m}$, con una orientación Noroeste-Sureste. La fachada cítrica es la Sureste, la cual, presenta algunas ventanas sin protección; pocos balcones originales con sus celosías, otros han sido cerrados formando muros ciegos; no presenta salientes, y poca vegetación frente a ella. Las protecciones solares para las ventanas, se sugiere que sean aleros o parasoles horizontales y/o verticales con una distancia mínima a la fachada de 1.2m. Los árboles que rodean a las edificaciones, deben ser nativos, caducifolios, grandes (altura de $16 \mathrm{~m}$ y ancho de copa 12m), densos con hojas pequeñas y separados a una distancia de $15 \mathrm{~m}$ de la fachada, para que generen sombras en las fachadas, pavimentos o suelos que las rodean.

La vegetación en el edificio B, presenta grandes árboles con una separación de 11 y 17 de la fachada, con una transmisividad del 85 y 65\% respectivamente, se recomienda que sean árboles con una menor transmisividad.

En el edificio C, de cinco niveles con una altura de 15m, con una orientación Noroeste-Sureste. La fachada de mayor ganancia solar es la Suroeste, es un muro ciego, sin ventanas, ni puertas, ni salientes. Las horas críticas se presentan de 13 a 17 horas. Se necesitan protecciones solares en toda la fachada, para evitar el sol en los ángulos solares desde 89 a ㅇ․ Las protecciones pueden ser doble muro con celosía o parasoles verticales u horizontales que se puedan manipular para que la radiación solar ingrese en invierno.

La vegetación en el edifico C, presentan árboles de tamaño mediano, con una transmisividad de 30, 25, 20, 15 y $10 \%$. En algunas partes, no presenta arborización frente a la fachada. Se recomienda aumentar los árboles de tamaños grandes y agrupados en conjunto. Con respecto al viento se considera que la separación entre los edificios varía entre 40 y 60m, beneficia para que el aire fluya alrededor de ellos; durante la mañana el viento apenas se percibe y es durante la tarde cuando aumenta su velocidad, predomino la dirección Sureste la cual coincide con la fachada del edificio C, el cual presentó las temperaturas más bajas en la superficie. El edificio A recibe las mayores velocidades del viento en la fachada Este, y los edificios B y C reciben las mayores velocidades en las Fachada Sureste. 


\section{Conclusiones}

Al ser el objetivo de este trabajo: "Analizar en corto tiempo y recursos propios, el comportamiento ambiental de los edificios del Multifamiliar, para extraer recomendaciones aplicables a las nuevas edificaciones de interés social que carecen de diseño bioclimático en clima cálido húmedo", se muestra la alta humedad promedio de 78\% en los años 1981 -2010 y en los años 2012-2013 del 85\%; con $81 \%$ de los días del año se encontraron nublados y sólo el $19 \%$ despejados. Para el alto porcentaje de humedad permanente en Tampico y con temperaturas promedio superiores a los 28으 en los meses de mayo a septiembre, la ventilación se convierte en una herramienta a considerar como sistema pasivo.

El estudio con el programa Comfort Ex evidencia dos periodos de disconfort, en calor y frío. El ciclo más largo es en calor, de los años de 1981 al 2010, es de seis meses de abril a septiembre y del 2012 al 2013 se presentó de marzo a octubre. El disconfort en el periodo frío, aunque es más corto, diciembre, enero y febrero, es muy intenso, por lo cual también se requieren actuaciones para este disconfort.

Con el programa Heliodon se determinó, que las edificaciones de Tampico necesitan protecciones solares en los meses de abril a octubre, en las fachadas Oeste desde $89^{\circ}$ a $0^{\circ}$; al Este desde los $60^{\circ}$ y del Este-Sureste desde los $53^{\circ}$, del Sur desde los $68^{\circ}$ y del Oeste-Noroeste durante todo el día. La fachada más crítica es la Noroeste seguida por la fachada Oeste que recibe 7 horas de radiación solar durante el día.

Si bien la dirección del viento reinante fue del Sureste, el flujo de viento se presenta en todas las direcciones con velocidades en la escala de Beaufort, de viento en calma de 0 a 0.5, brisa muy suave de 0.6 a 1.5, brisa leve de 1.6 a 3.3 y en brisa suave de 3.4 hasta 4.7. Las velocidades altas, se presentaron durante la mañana con dirección Sureste y Suroeste; en la tarde del Suroeste y Noreste. Las velocidades más altas se registraron de 11 a 17 horas con dirección Sureste.

El flujo de viento en barlovento estuvo presente en el edificio A en la fachada Sur, y en los edificios B y C en las fachadas Sureste. La separación entre los edificios de cuatro veces su altura, permitió que la sombra de viento generada frente a la fachada Noroeste del edifico C, no interviniera con el flujo de aire que recibieron los edificios A y B con las mismas velocidades que el edificio C.

La vegetación tiene poca influencia en la reducción de la temperatura del aire, se mantuvo abajo de $1^{\circ} \mathrm{C}$, pero sí en la temperatura media radiante, ya que la superficie de la misma vegetación presenta una disminución de $3^{\circ} \mathrm{C}$. Se recomienda utilizar vegetación en todas las fachadas para su protección solar, con copas amplias de más de $10 \mathrm{~m}$ de diámetro y mayores de $12 \mathrm{~m}$ de altura.

\section{Recomendaciones de diseño}

Tampico al ser considerada como una ciudad tropical, debido a su clima cálido húmedo con un promedio de humedad relativa (HR) del $85 \%$, característica por la cual se recomienda que losas y muros de las edificaciones sean de materiales ligeros de escasa inercia térmica. Los techos altos, a más de $3 \mathrm{~m}$ con aberturas en la parte superior de las fachadas para que el aire caliente pueda salir $y$, en consecuencia, permita que la circulación del aire saque o reduzca la sensación de humedad y refresque las habitaciones, también se pueden utilizar bóvedas o chimeneas para ventilar. 
Con temperaturas medias de mayo a septiembre superiores a los $28^{\circ} \mathrm{C}$, se recomienda orientar los edificios sobre el eje Este- Oeste donde sus fachadas más largas se ubiquen al Norte y Sur, para reducir la exposición al sol, deberán estar protegidas de la radiación directa y difusa, y de la lluvia. Las edificaciones deberán ser porosas, con materiales ligeros de escasa inercia térmica. Los colores al exterior deben ser claros, para que la radiación incidente se refleje al exterior e ingrese la menor energía térmica posible al interior.

Se requieren protecciones solares verticales o dobles fachadas con celosías al poniente, Ya que permitirán la ventilación de la fachada, para que el aire caliente ascendente pueda fluir libremente. Los dispositivos al exterior como toldos, persianas o lamas, que son flexibles son una buena opción a los cambios estacionales. Es necesario utilizarlos frente a las fachadas Suroeste, Oeste y Noroeste, fijos y/o variables, calculados de acuerdo a la trayectoria del sol, otra opción son los aleros y/o muros.

La arborización en espacios abiertos, banquetas y camellones se hace necesaria para reducir el flujo de radiación solar hacia las fachadas y circulaciones peatonales. Los árboles deben ser con copas amplias de más de $10 \mathrm{~m}$ de diámetro y mayores de $12 \mathrm{~m}$ de altura, de hoja caduca para que en invierno al perder sus hojas dejen pasar la radiación solar y en verano en las horas críticas, proporcionen sombras en fachadas, suelos y pavimentos.

Los edificios deberán ser, de formas alargadas, de preferencia ubicados a una distancia de 1.5 veces su altura, para que la sombra del viento, no interfiera con los edificios de atrás. La ventilación natural, se recomienda en los meses, desde marzo hasta octubre. Las construcciones deben estar separadas, con formas alargadas. Las ventanas deben estar a los vientos reinantes del Este y Sureste para asegurar el movimiento del aire con una ventilación cruzada y con aberturas al Norte, Noreste y Suroeste; de diferentes tamaños, y la más grande ubicada en la salida del aire, para obtener una mayor velocidad al interior.

Los edificios deben estar separados para que fluya el viento, aprovechar la dirección Este y Sureste, ubicando las construcciones oblicuas al viento. Los árboles deben estar separados de 12 a 15 metros de las fachadas para que generen sombras en los suelos y pavimentos y dejen fluir el aire a través de los espacios abiertos. Para invierno, cuando el periodo de disconfort es frío, se hace necesario que las fachadas reciban mayor radiación solar, y menos viento en los meses de diciembre, enero y febrero.

\section{Agradecimientos}

A la Universidad Autónoma de Tamaulipas por el otorgamiento de la beca y a las estudiantes de la Facultad de Arquitectura, Diseño y Urbanismo de la UAT Hillary Shaden Rodríguez Lerma y Rosa Patricia Torres Fajardo, por su colaboración,

\section{Autoría}

La primera autora ha diseñado y escrito la investigación, el segundo autor ha revisado la estructura y analizado los datos y la tercera autora ha revisado la metodología y estructura.

Conflicto de intereses: Los autores declaran que no hay conflicto de intereses. 


\section{Bibliografía}

Beckers, B; \& Masset, L. (2006). Heliodon 2 Recuperado de http://heliodon.net/heliodon/index.html

Corburn, J. (2009). Cities, Climate Change and Urban Heat Island Mitigation: Localising Global Environmental Science. Urban Studies, 46(2), 413-427. DOI: https://doi.org/10.1177/0042098008099361

Higueras, E. (2012). Urbanismo solar. Manual de buenas prácticas bioclimáticas para la localidad de Vitoria -Gasteiz. Convenio Instituto Juan Herrera - Ayto. Vitoria Gasteiz. Madrid. Junio. Recuperado de https://www.vitoria-gasteiz.org/docs/wb021/contenidosEstaticos/adjuntos/es/22/86/52286.pdf

Higueras, E. (2006). Urbanismo Bioclimático. Barcelona. España. Gustavo Gili, SL.

García, E. (1990). Climas, 1: 4000 000. IV.4.10 (A). Atlas Nacional de México. Vol. II. Instituto de Geografía. UNAM, México.

Givoni, B. (1976). Man Climate and Architecture. 2nd. Edition. London. Elsevier.

Gonzalo, G. (2004). Manual de Arquitectura Bioclimática. 2a Edición. Buenos Aires. Nobuko.

Instituto Nacional de Estadística y Geografía. INEGI. (2010). Censo de población y vivienda. México. Recuperado de: http://www.beta.inegi.org.mx/proyectos/ccpv/cpvsh/default.html

López-Ordoñez, C.F.; Roset, J; \& Rojas-Cotorreal, G. (2010). Análisis de la radiación solar directa en las calles de Barcelona, en base a la relación entre su morfología y vegetación. ACE: Architecture, City and Environment 12(34), 45-68. DOI: http://dx.doi.org/10.5821/ace.12.34.4708

Loredo, R. (2018). Revisión histórica de la vivienda colectiva en el entorno de la Laguna del Carpintero en Tampico, Tamaulipas (1920-1960). En: Bartorila, M. y Rosas-Lusett, M. (Eds). Revitalización Urbana, aportaciones para la ciudad vertical. México. Colofón. 23-43.

Moreno, M. (1993). Estudio del clima urbano de Barcelona. La isla de calor. Barcelona. España. Editorial, Solgraf, S.A.

Ochoa, J.M. (2009). Ciudad, vegetación e impacto climático. El confort en los espacios urbanos. Erasmus Ediciones. Barcelona. España.

Olgyay, V. (2006). Arquitectura y clima. Manual de diseño bioclimático para arquitectos y urbanistas. Editorial Gustavo Gili, SL. Barcelona. España.

Pani, M. \& Ortega, S. (1952). El centro urbano Presidente Juárez. Editorial, Arquitectura México. No. 40. 375-418.

Rein, M. (2013). El confort urbano en la ciudad y su evolución en los últimos años. Territorio y configuración de la ciudad. Agenda 21. Ayuntamiento de Málaga. Recuperado de http://www.rvarquitectas.com/pdf/701-informe-agenda-21-1.pdf

Rosas-Lusett, M. y Bartorila, M. (2017). Aportaciones de la forestación a la sostenibilidad urbana en ciudades tropicales. Humedal Nuevo Amanecer, ciudad Madero México. Nova Scientia, I(3), 36-41 DOI: https://doi.org/10.21640/ns.v9i19.980

Serra, R. y Coch, H. (2001). Arquitectura y Energía Natural. Barcelona, España. Ediciones UPC.

Sistema Meteorológico Nacional. Gobierno de México. Recuperado de https://smn.conagua.gob.mx/es/climatologia/informacion-climatologica/mapas-de-climatologia-1981-2010

Terradas, J. (2001). Ecología Urbana. Barcelona, España. Rubes Editorial, S. L.

Yáñez, G. (2008). Arquitectura solar e iluminación natural. Editorial Munilla-Lería. Madrid. 